Article

\title{
Strategically Targeting Plug-In Electric Vehicle Rebates and Outreach Using "EV Convert" Characteristics
}

\author{
Brett D. H. Williams * and John B. Anderson \\ Center for Sustainable Energy (CSE), 3980 Sherman St. Suite 170, San Diego, CA 92110, USA; \\ john.anderson@energycenter.org \\ * Correspondence: brett.williams@energycenter.org
}

check for updates

Citation: Williams, B.D.H.;

Anderson, J.B. Strategically Targeting Plug-In Electric Vehicle Rebates and Outreach Using "EV Convert" Characteristics. Energies 2021, 14, 1899. https://doi.org/10.3390/ en14071899

Academic Editor: Rui Xiong

Received: 27 February 2021

Accepted: 25 March 2021

Published: 30 March 2021

Publisher's Note: MDPI stays neutral with regard to jurisdictional claims in published maps and institutional affiliations.

Copyright: (C) 2021 by the authors. Licensee MDPI, Basel, Switzerland. This article is an open access article distributed under the terms and conditions of the Creative Commons Attribution (CC BY) license (https:// creativecommons.org/licenses/by/ $4.0 /)$.

\begin{abstract}
To expand markets for plug-in electric vehicles (EVs) beyond enthusiastic early adopters, investments must be strategic. This research characterizes a segment of EV adoption that points the way toward the mainstream: EV consumers with low or no initial interest in EVs, or "EV Converts." Logistic regression is utilized to profile EV Convert demographic, household, and regional characteristics; vehicle-transaction details; and purchase motivations-based on 2016-2017 survey data characterizing 5447 rebated California EV consumers. Explanatory factors are rank-ordered-separately for battery EVs (BEVs) and plug-in hybrid EVs (PHEVs), to inform targeted outreach and incentive design. EV Converts tend to have relatively "lower" values on factors that might have otherwise "pre-converted" them to EV interest: hours researching EVs online; motivation from environmental impacts and carpool-lane access; and solar ownership. PHEV Converts more closely resemble new-car buyers than other EV adopters, and BEV Converts actually tend to be younger and less-frequently white/Caucasian than new-car buyers. BEV Converts also tend to: lack workplace charging, be moderately motivated by energy independence, and reside in Southern California or the Central Valley. Predictors that not only help target consumers, but also help convert them, include rebates for BEV consumers and, modestly, fuel-cost savings for PHEV consumers.
\end{abstract}

Keywords: electric vehicle; EV; adopter characteristics; consumer segment; outreach strategy; incentive design

\section{Introduction \\ 1.1. Problem}

The market share of plug-in electric vehicles (EVs) remains modest despite substantial public and private investments to promote EV awareness and adoption. Large increases remain in order to meet aggressive goals to transform private transportation into a more sustainable energy system. As such, the targeting of supportive resources, such as marketing/education/outreach, incentives, and other measures, should aim to strategically expand the frontiers of the EV market.

This research begins to address an important gap in our understanding of how to strategically expand EV markets by exploring the intersection between "what is working" in EV markets (current adoption), and "where EV markets need to go for commercialization to be more widespread" (beyond enthusiastic early adopters). It asks not just "Who is adopting?" but "Which segments of that adoption inform strategies for moving forward?" and not just "Where do we need to end up?" but "What steps point the way?" How can EV markets move in a targeted way beyond enthusiasts and toward the mainstream?

As detailed next, the bulk of previous research has typically used hypothetical-choice models and other methods to elicit the stated preferences of consumers without experience with EVs. This can provide "reality checks" from non-enthusiasts that better calibrate expectations about future adoption, but remain hypothetical. The smaller but growing body of research analyzing data from actual adopters of EVs typically use clustering techniques 
to identify subgroups within the data to increase the resolution of our understanding EV markets, but those clusters can vary in their ease of interpretation and actionability. This work aims to examine a targeted and targetable subgroup of consumers that have bridged the gap between EV inexperience and adoption.

\subsection{Approach, Previous Research, and Contributions}

Characterizations based upon ex-post/revealed-preference data. This work characterizes a market segment of less-enthusiastic, more-mainstream EV consumers (described below). As such, it adds to a modest but growing body of research and program reporting that characterize and/or segment actual past adopters of EVs [1-15]. In contrast to stated-preference analyses that ask consumers questions related to their proclivity to adopt an EV (e.g., see literature summaries by Dua et al. [3] and Lee et al. [4]), analyses like this one used ex-post-/revealed-preference data to characterize those that have adopted. As such, the adoption behaviour is not hypothetical and the analysis is accordingly less likely to suffer from certain biases, failure to fully account for constraints on adoption, or other factors that potentially disconnect stated-preference analyses from actual market participants behaviours [16-18]. However, revealed-preference studies can be limited by market-data availability or tied to the outdated characteristics of early past adopters in a growing and evolving market. Although not immune to these limitations, this work examines revealed-preference data to characterize a set of actual adopters that is relatively large $(n=5447)$ and who purchased/leased EVs relatively recently (2016-17) — several years and vehicle generations after the 2010 initial launch of the U.S. EV market. Even though the market is rapidly evolving, this work nevertheless represents an update to prior work and an expansion of a nascent but increasingly important emergent body of work focused on the segmentation of EV consumers aimed at strategically accelerating and expanding the market, rather than simply characterizing past adoption overall.

Characterizations of a segment of pre-determined strategic interest. In contrast to clustering or using other techniques to determine segments of past (or potential) adopters [3,4,19], this work examines a pre-determined segment of interest-consumers with low initial interest in EVs that went on to adopt, or "EV Converts." It uses binary logistic regression to identify characteristics that statistically help explain membership in the EV Convert segment.

Outside of work by the authors, the single study (reported in two parts $[20,21]$ ) most methodologically and conceptually similar to this work used logistic regression of survey data to model the level of consideration a respondent has given to buying EVs for their household. That study is largely based upon the stated preferences of car buyers and models consideration of PHEVs, BEVs, and fuel-cell EVs together in a single, zero-emission-vehicle (ZEV) model approach. In it, Kurani highlights the low levels of EV awareness and consideration in the general car-owning population and models characteristics associated with EV purchase consideration level. In a similar vein to this work, that study models characteristics associated with its dependent variable to help identify strategies and targets for growing the EV market-in that case by increasing overall awareness, understanding, and consideration of EVs. Notably, that study does not claim to produce accurate predictions of purchase consideration, acknowledging limitations in its ability to do so, but rather emphasizes the value of the explanatory associations: "Because high levels of consideration, e.g., active shopping including test drives and vehicle acquisition, remain such low incidence events across the general population of car-owning households, no model accurately estimates which respondents have already given the highest consideration to a ZEV for their household. However, the models are still useful for pointing to measures that are correlated with higher levels of consideration," ([20], p. 34).

The work herein similarly identifies, but also prioritizes the importance of, characteristics associated with a measure of personal engagement with EVs-in this case, the level of initial interest in EVs at the beginning of a consumer's car search. The level of purchase consideration is a related but distinct dependent variable as compared to "in- 
terest" in EVs. Indeed, modelling in that study includes an "interest"-related independent variable-specifically, the consumer's [current] interest in the technical details of vehicles that run on electricity and hydrogen. It is notable that this "interest in ZEV technology" variable, also related to but distinct from the "initial interest in EVs" dependent variable examined in this work, was found to be significantly associated with purchase consideration. Further, it was shown to be more explanatory than more general technology innovativeness measures, displacing them when added to the modelling. It thus represents a loose conceptual link to the initial interest in EVs examined here, allowing the three concepts to be compared/contrasted, and findings about them to be "verified," or at least set against each other and examined for consistency. For example, that study largely discounts the use of socio-demographic variables because they were mostly displaced as other variables with more explanatory power were added to the modelling. However, certain demographic variables were found to be significant in this work on initial interest, primarily for BEV consumers in the technology-type-specific modelling used herein. Perhaps this adds more nuanced/layered ways of thinking about demographics. For example, demographics might be considered both: (1) in a conceptually nested way, as helping to explain "interest" type concepts, which in turn more directly explain purchase consideration, and (2) in an actionable way, as widely available to help target those consumers who might be most ripe for "conversion" among the larger body of mainstream consumers.

This work is also distinct from that study in its aims and focus. The Kurani study aims to find ways to increase very low EV purchase consideration to the very high levels ultimately needed for major market transformation: "[T]here seems very little prospect to grow the ZEV market very far, very fast unless the vast majority of car-owning households in California who are not paying attention can be engaged in the transition to electricdrive," ([20], p. 40). In this sense, it focuses on what is ultimately needed (the vast majority of consumers considering ZEVs) and tries to find ways to get there. However, it concedes, "Certainly, we should not expect all of the people who have so far paid no or little attention will be or can be quickly converted to being ZEV shoppers and owners," (p. 40). To that point, this work focuses specifically on the type of consumer that has been converted during the span of their car search. The EV Converts segment was so named in 2016 precursor work [22] because its members combine both (1) no or low initial interest in EVs at the start of their search and the (2) fact that they all have gone on to adopt nevertheless-implying they have experienced a conversion along the way. As such, $E V$ Converts (and what they can tell us about potential consumers like them) represent one strategic "place to start" using policy and other supportive measures to effectively "convert" non-enthusiastic, more mainstream consumers to EV adoption. In a sense, this research works in the opposite direction as the approach taken in Kurani (2018): rather than working back from a conception of the full magnitude of what is ultimately needed, this research focuses on what is already working/happening and aims to find ways to amplify those dynamics to help progress the market forward. It is hoped that doing so will be supportive of the larger transformation, and the two lines of research will "meet in the middle," connecting the dots between what is needed and effective places to start. In a resource-constrained world, it is hoped a strategic focus on segments like EV Converts provide actionable next steps down the road toward achieving widespread increases in not only consideration, but also adoption, by mainstream markets.

Previous efforts by the authors to analyse strategic EV target market segments in a manner similar to this work include characterization of California consumers highly influenced by rebates to purchase/lease EVs, or the "Rebate Essential" consumer segment: A 2017 journal article characterized Rebate Essential adopters of plug-in hybrid EVs (PHEVs) during the 2013-15 time frame [23]. A conference paper furthered this approach and applied it to adopters of both PHEVs and all-battery EVs (BEVs) in the 2016-17 time frame [24]. Work examining "EV Converts" specifically used older data and has only been presented to conferences to date $[22,25,26]$. This work updates (with 2016-17 data) and formalizes those prior preliminary examinations of $E V$ Convert consumers. Similar to previous work on both 
Rebate Essentials and EV Converts, this work utilizes a binary logistic regression to identify factors-demographic, household, and regional characteristics; purchase motivations; and vehicle-transaction details-that significantly increase the odds of being an $E V$ Convert. It examines consumers of PHEVs $(n=2276)$ and BEVs $(n=3171)$ separately to account for their unique qualities.

The findings described below highlight the differing characteristics and motivations between EV Converts and typical EV adopters. These characteristics help us understand or reinforce our ideas about what it is to lack initial interest in EVs, but shows us how those characteristics can be embodied in a group that did nevertheless go on to adopt, perhaps pointing the way forward. Indeed, nearly all EV Convert demographics lie somewhere in-between typical EV adopters and new-car buyers as a whole. Some BEV Converts characteristics even "go beyond" new-car buyers, painting a younger and more ethnically diverse picture than expected of past adopters. These findings also speak to factors and experiences that $E V$ Converts lack that might have otherwise "pre-converted" them (such as environmental motivations and workplace charging), as well as some that may have helped them convert, including rebates and the promise of fuel-cost savings.

\subsection{Section Overview}

The next section (Section 2) details the data and methodology used to characterize $E V$ Converts. Section 3 describes descriptive and modelling results, including discussion of both significant and notable nonsignificant findings, comparison to previous results and descriptive measures, and rank-ordering by relative importance to facilitate triage in outreach campaigns and incentive designs. Finally, Section 4 provides summary, conclusions, caveats, and thoughts on ways EV Convert findings can support EV adoption.

\section{Materials and Methods}

\subsection{Data and Representativeness}

The California Clean Vehicle Rebate Project (CVRP) provides cash rebates to consumers for the purchase or lease of clean vehicles. CVRP administers a Consumer Survey for rebated nonfleet individuals. Participants receive an invitation to the online survey upon approval of their rebate application and a reminder invitation as part of correspondence indicating their check has been sent. Response rates in excess of $20 \%$ are typical across survey editions over time and described in further detail for the 2013-15 Edition in a summary of the survey's administration and response distributions [12,15].

The research summarized herein used PHEV and BEV consumer data from the 2016-17 edition of the CVRP Consumer Survey (Table 1).

Table 1. California CVRP Consumer Survey, 2016-17 Edition a .

\begin{tabular}{ll}
\hline Administration Dates & 19 July 2016-31 August 2017 \\
\hline Purchase/Lease Dates & 1 May 2016-31 May 2017 \\
\hline & $\mathrm{N}=46,839$ \\
Plug-in EV Portion of Program Participant Population & $\bullet \quad$ PHEVs $=18,335$ \\
\hline & $\bullet \quad$ BEVs $=28,504$ \\
Plug-in EV Responses in Dataset & $\bullet=8957$ \\
\hline Weighting Method & $\bullet \quad$ BEVs $=5411$ \\
\hline Representative Dimensions & Iterative proportional fitting (aka raking, post-stratification) \\
\hline Program as \% of Plug-in EV Market & Vehicle tech. type, model, purchase vs. lease, residence county \\
\hline
\end{tabular}

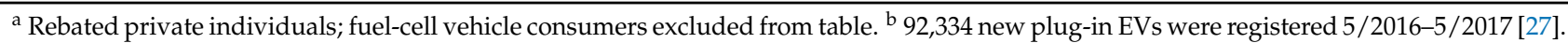


Note that CVRP and California Air Resources Board regulations treat range-extended BEVs (or "BEVx" vehicles, a category which currently only includes the BMW i3 REx) as equivalent to all-battery BEVs in terms the size of the rebate they qualify for. Consistent with this, a modest number of BEVx vehicles are included within CVRP BEV counts in Table 1.

Application information, which is provided by all participants, is used to create response weights to make the data more representative of all program participants (Table 1). These weights are regularly used elsewhere $[12,15,28]$ and typically change results only modestly (e.g., response-frequency percentages typically only change by $0-2 \%$, as will be seen in Section 2.2). When seeking to strategically target CVRP program outreach and incentive design, CVRP participants are the population of direct interest. For those with less direct interests, the total EV market is not necessarily perfectly represented by CVRP participants. However, over this period, CVRP participants constituted over half of California's plug-in EV market (Table 1). The data upon which Table 1 is based-rebate and survey-response counts by vehicle category and purchase/lease month-is available for download in an online repository [29].

\subsection{Methodology}

Overview. The overall objective was to characterize EV Converts. The descriptive analysis used weighted response frequencies to produce pertinent demographic metrics for EV Converts and to provide context for those metrics with appropriate baselines of comparison. The modelling approach was binary logistic regression with the outcome variable constructed from the survey question, "Which of the following statements best describes your interest in acquiring a plug-in electric vehicle (PEV) when you started your search for a new vehicle?" Consumers who responded, "I did not know PEVs existed," "I had no interest in a PEV," or "I had some interest in a PEV" are grouped to form the EV Convert status. Respondents who said, "I was very interested in a PEV," "I was only interested in a PEV, but considered multiple PEV makes/models," or "I was only interested in the specific PEV make/model I acquired" were grouped to form the nonconvert status (Figure 1). The data upon which Figure 1 is based-the number of survey responses per response category by technology type-is available for download in an online repository [29].

The predictor variables include other survey responses and application details characterizing the consumer, household, vehicle, and transaction. Results of a Full Model were examined for significance and notable nonsignificance. Parsimonious Model results were ranked according to how much they increase the odds of being an EV Convert.

General Data Preparation. Several data-preparation steps are worth noting. The purchase/lease date range was trimmed to begin 1 November 2016, after CVRP's introduction and adjustment of income-based rebate eligibility criteria [30]. This left only those of the "current program-design era" (PHEV = 2339, BEV = 3277). Weighted data were used for the descriptive analysis to make them better represent the rebate population characterized, but unweighted data were used for the logistic regressions to reduce standard errors and bias, and to increase consistency [31]. PHEV and BEV consumer data were treated separately, due to the differences in associated consumer demographic, psychographic, and housing characteristics; incentive influence; and driving and charging behaviours [32-38]. Fifteen cases were removed that lacked the response necessary to determine EV Convert status. 17 $\mathrm{BEV}$ purchase prices (all less than $\$ 20,000$ ) were removed as potentially problematic. 


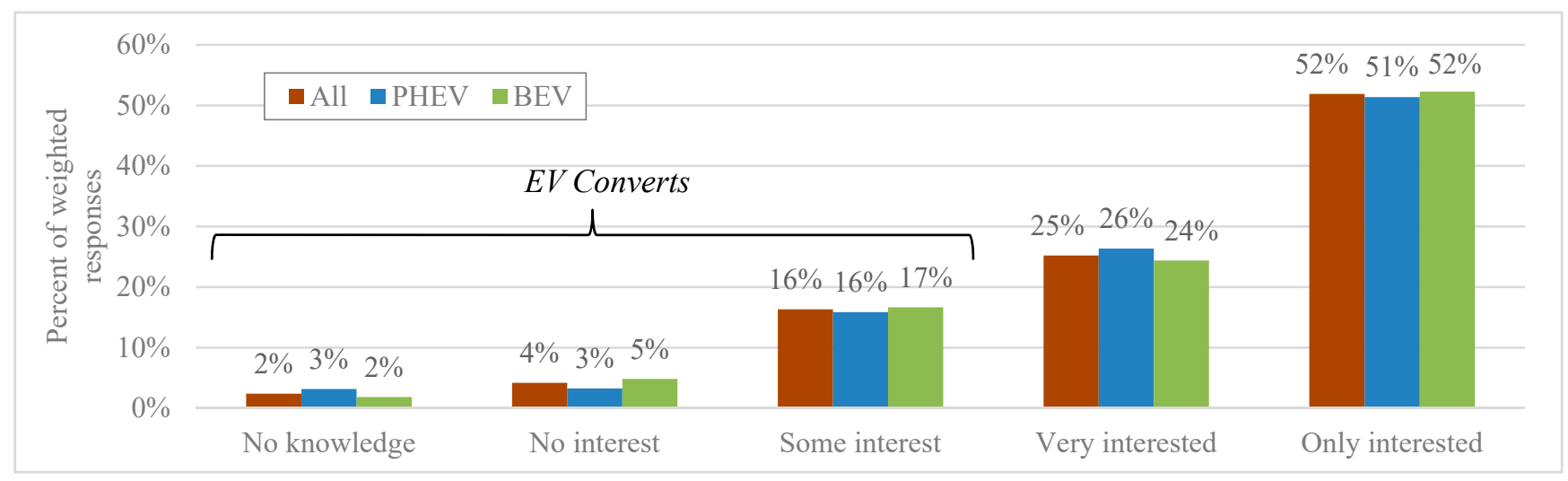

Figure 1. Knowledge of or Interest in a PEV at the Start of the New Car Search (data available: [29]).

Predictor (Explanatory) Variable Preparation. The predictor variables were largely sourced from the Consumer Survey, but also include CVRP vehicle and applicant data. Note that not all predictor variables should be interpreted in the same way, as some are strictly explanatory in nature. Causality is not analysed here, rather, the predictor variables are used in their typical general sense, to predict the odds of a consumer being an $E V$ Convert or not. Several selected variables were discarded due to concerns about collinearity with other predictor variables. Some variable bins were combined to ensure adequate cell size [39] (vehicle make, region, income, and number of previous EVs). Variables with numerous related response options were consolidated into categories (e.g., reasons for adopting). Some variables consist of ordinal binned values representing underlying continuous metrics (e.g., income). In these cases, alternative variable data formats (i.e., continuous vs. categorical) were evaluated by regressing the format options against the outcome variable and, if different, the format with the best fit was used [40]. Included variables are summarized in Appendix A.

Missing Data. Appendix A also shows the proportions of missing data. The highest proportion occurs for household income, but the missingness rate $(\sim 12 \%)$ is less than rates achieved in other surveys [41]. Racial/ethnic identity had the next-highest non-response rate (over 9\%). Two variables constructed to count the number of reasons that either pushed or pulled the consumer to acquire and EV (neither of which ended up being significant in any model) had missingness rates over $6 \%$. Missingness rates were less than $3 \%$ of cases for the other variables. Missing data were addressed in two stages. First, listwise deletion was applied to variables with missingness less than $1 \%$ (PHEV and BEV combined). Total reduction of the sample size resulting from listwise deletion was roughly $3 \%$ or less. Then, multiple imputation was applied. This was necessitated by the income variable, for which missingness is not assumed to be missing completely at random. Variability was generated by producing twenty imputed datasets, thereby addressing the limitations of single imputation [42].

Final Analytical Datasets. After trimming to the current program era, deleting cases, and imputing missing values, the analytical datasets consisted of $n=2276$ for PHEV consumers and $n=3171$ for BEV consumers. Table 2 lists the plug-in EV models in the dataset to provide context on the state of the EV market and the types of vehicles purchased or leased by the consumers analyzed. Table 3 summarizes ratio and interval variables, for PHEVs and BEVs separately. It provides the percent of the total cases missing values, the average and standard deviation of the data, and the average calculated using the weights described in Table 1 to make the data more representative of the program as a whole. Appendix A summarizes the data for all other variables (ordinal and categorical), including missingness percentages, frequency percentages, and weighted frequency percentages. 
Table 2. EV Models Purchased or Leased by Analyzed Consumers.

\begin{tabular}{ll}
\hline PHEV & BEV \\
\hline Audi A3 e-tron & BMW i3 \\
Chevrolet Volt & BMW i3 REx \\
Chrysler Pacifica & Chevrolet Bolt EV \\
Ford C-MAX Energi & Chevrolet Spark EV \\
Ford Fusion Energi & FIAT 500e \\
Hyundai Sonata Plug-in Hybrid & Ford Focus Electric \\
Kia Optima Plug-in Hybrid & Hyundai Ioniq Electric \\
Toyota Prius Prime & Kia Soul EV \\
& Mercedes-Benz B250e \\
& Nissan LEAF \\
& Tesla Model S \\
& Tesla Model X \\
& Volkswagen e-Golf \\
\hline
\end{tabular}

Table 3. Ratio and Interval Variable Data Summary.

\begin{tabular}{ccccccccc}
\hline & \multicolumn{1}{c}{ PHEV } & & & BEV \\
\hline & Missing & Average & Std. Dev. & Wghtd Ave. & Missing & Average & Std. Dev. & Wghtd Ave. \\
\hline $\begin{array}{c}\text { Vehicle } \\
\text { purchase/lease price }\end{array}$ & $0 \%$ & $\$ 33,427$ & $\$ 3690$ & $\$ 33,597$ & $0 \%$ & $\$ 44,791$ & $\$ 25,390$ & $\$ 43,946$ \\
\hline $\begin{array}{c}\text { Vehicle } \\
\text { purchase/lease date }\end{array}$ & $0 \%$ & 5 Feb 2017 & 60 days & - & $0 \%$ & 11 Feb 2017 & 55 days & - \\
\hline
\end{tabular}

Full Model Specification. Each dataset was used to produce a "Full Model" to explore the directionality and (non)significance of a comprehensive set of controlling and explanatory variables. Logistic regression was used to allow for identification and exploration of characteristics associated with EV Convert status while controlling for other characteristics. Multinomial logistic regression was not used because it does not take the ordering of categories into account. Ordered logistic regression was not used due to concerns about model assumptions, such as the requirement that the parallel regressions assumption is met [43]. Additionally, generalized ordered logistic regression was determined to add excessive complexity to the interpretation of the results [43] - particularly for outreach campaigns-in contrast to the intuitive "odds ratios" produced herein (described below).

As such, binary logistic regressions were fit using all predictor variables listed in Section 3.2 for each of the 20 datasets produced in the multiple imputation procedure. The results were pooled using Rubin's rules via the MICE library in the statistical package $\mathrm{R}[44,45]$. Scatter plots of continuous predictors vs. the fitted logit values were examined for linearity [46]. Continuous variables of concern were examined to see if categorical treatment would address nonlinearity issues (e.g., the number of reasons that pushed a consumer to acquire). Transformed variables were tested by regressing continuous and transformed categorical formats of the variable against the output variable to confirm categorical treatment was acceptable. Initial exploration of the effect of three potential outlier observations in the BEV model was done, but those observations were left in for this analysis. The model was then re-run and the new results were pooled. Using Wald tests, joint significance of variables with categorical responses was used to verify significance of individual category coefficients [39]. The results of these "Initial Full Models" are also displayed in Tables 5 and 6.

Parsimonious Model Specification. Each Initial Full Model was then reduced to a "Parsimonious Model" to provide a succinct set of the most meaningful predictors. Variables with variance inflation factors greater than 10 were considered for exclusion [39]. The collinearity between BEV make and price, the lack of significance for price, and the 
nonlinearity between price and the logit led to price being dropped. Overall, model reduction steps were:

1. Remove variables determined to be problematic due to covariance (BEV price, previously described), nonlinearity (BEV price), and/or conceptual overlap with the dependent variable (\# of EVs owned).

2. Consider removing insignificant variables with conceptually related predictor variables still included in the model (e.g., number of people in a PHEV household was removed and number of cars left in).

3. Produce a reduced interim model with problematic and overlapping/related predictors removed.

4. Use backward stepwise selection by Akaike information criterion to nominate predictors for deletion.

5. Produce a further reduced PHEV model, leaving in select insignificant variables of particular program interest that were significant in the BEV model (Rebate Essentiality, income, and race/ethnicity).

6. Produce a Parsimonious Model with only significant predictors, verifying joint significance.

Dominance Ranking. To facilitate prioritization of predictors, a dominance analysis was performed $[47,48]$. Dominance analysis measures the impact of removing a predictor from the model. Here, the Average Contribution, a measure of the average change in pseudo- $R^{2}$ [47,48], was produced for each of the 20 versions of each Parsimonious Model. These 20 Average Contribution values were in turn averaged and rank-ordered.

\section{Results and Discussion}

\subsection{Descriptive Results and Discussion}

The rebated PHEV and BEV consumer populations are the baseline against which findings about PHEV Convert and BEV Convert segments should be compared. For example, a regression result that the odds of being an $E V$ Convert are increased with younger age should not be thought of simply as "young people." Rather it should be considered relative to the age of the population in which the segment sits. Compare the metrics of age in Table 4 for the population of rebated BEV consumers ( $47 \%$ over 50 years old) to the BEV Convert segment (38\%). [Following the convention established in Figure 1, the colors in Table 4 and throughout are used to indicate results applicable to PHEVs specifically (in green), BEVs specifically (in blue) or both (in dark orange).]

Table 4 also allows comparison of both the BEV adopter population and BEV Convert segment to a measure of the new-car-buying market overall (46\% of whom are estimated to be 50 or more years old). In this case, the segment appears younger than both the EV population and the market, but for most other characteristics the segment appears to be between the EV population and the market. As such, each EV Converts segment is a margin of existing EV adoption that might be strategically grown to advance adoption more toward, or even beyond, the mainstream. 
Table 4. Summary of EV Convert Characteristics ${ }^{\text {a }}$.

\begin{tabular}{|c|c|c|c|c|c|c|}
\hline & \multicolumn{5}{|c|}{ Rebated Consumer Population and Segments the Analytical Dataset Represents } & \multirow[b]{2}{*}{$\begin{array}{l}\text { CA New-Vehicle Buyers } \\
\text { MYs 2016-17 } \\
\text { (2017 NHTS } \\
\text { CA Add-On [49]) }^{c}\end{array}$} \\
\hline & $\begin{array}{c}\text { All } \\
\text { (Weighted } \\
n=5327)\end{array}$ & $\begin{array}{c}\text { BEV b } \\
\text { (Weighted } \\
n=3097)\end{array}$ & $\begin{array}{c}\text { BEV Converts } \\
\text { (Weighted } \\
n=723)\end{array}$ & $\begin{array}{l}\text { PHEV b } \\
\text { (Weighted } \\
n=2230 \text { ) }\end{array}$ & $\begin{array}{l}\text { PHEV Converts } \\
\text { (Weighted } \\
n=497)\end{array}$ & \\
\hline Selected solely White/Caucasian & $58 \%$ & $57 \%$ & $46 \%$ & $60 \%$ & $56 \%$ & $51 \%$ \\
\hline$\geq 50$ Years Old & $50 \%$ & $47 \%$ & $38 \%$ & $53 \%$ & $46 \%$ & $46 \%$ \\
\hline$\geq$ Bachelor's Degree in $\mathrm{HH}$ & $81 \%$ & $83 \%$ & $80 \%$ & $78 \%$ & $77 \%$ & $58 \% \mathrm{~d}$ \\
\hline Own Residence & $79 \%$ & $81 \%$ & $73 \%$ & $76 \%$ & $70 \%$ & $63 \%$ \\
\hline$\geq \$ 100$ k HH Income & $68 \%$ & $71 \%$ & $61 \%$ & $64 \%$ & $58 \%$ & $56 \%$ \\
\hline Selected Male & $72 \%$ & $73 \%$ & $67 \%$ & $70 \%$ & $68 \%$ & $50 \%$ \\
\hline
\end{tabular}

a The data upon which Figure 1 is based-the number of survey responses per response category by technology type-is available for download in an online repository [29]. "Prefer not to answer," "I do not know," and similar responses are excluded. Weighted percentages presented. ${ }^{\mathrm{b}}$ The BEV and PHEV populations examined here are statistically different $(p<0.05)$ on all dimensions except gender and race/ethnicity. ${ }^{c}$ NHTS is weighted to represent the entire population, not those with new vehicle specifically. The new-vehicle-buyer subset is defined here as those whose odometer reading and miles driven match within 100 miles. ${ }^{\mathrm{d}}$ NHTS data characterize individual educational attainment, whereas other data characterize highest household attainment.

\subsection{Modeling Results and Discussion}

Expressed as odds ratios (OR), the results in Tables 5 and 6 show by how much the odds of being an $E V$ Convert change if the predictor variable of interest increases by one unit, holding all other predictor variables constant. Odds ratios greater than one indicate an increase in the odds of being an EV Convert (a positive association), while odds ratios less indicate decreased odds (a negative association). For example, if identification as male has an odds ratio of 0.79 , it is associated with a $21 \%$ decrease in the odds of being an EV Convert. Odds ratios should not be compared across predictor variables: for example, a one-dollar change in vehicle price is not comparable to a one-day change in purchase date. Significance findings at the 95\% level $(p<0.05)$ are indicated in Tables 5 and 6 by an asterisk and cell shading. Green shading is used for a variable with a positive association with $E V$ Convert status $(\mathrm{OR}>1)$ and red for negative association $(\mathrm{OR}<1)$. Additionally, several instances of variables with $p<0.10$ have no asterisk but are lightly shaded to highlight candidates for further exploration in more parsimonious or alternative model specifications.

Table 5. PHEV Variables and Model Results.

\begin{tabular}{|c|c|c|c|c|c|}
\hline Variable Description & Example Values & Missing & $\begin{array}{c}\text { Initial Full } \\
\text { Model Odds } \\
\text { Ratio } \\
\end{array}$ & $\begin{array}{c}\text { Pars. } \\
\text { Model } \\
\text { Odds Ratio }\end{array}$ & $\begin{array}{l}\text { Dom. } \\
\text { Rank }\end{array}$ \\
\hline (Intercept) & & & 300.31 & 0.33 * & \\
\hline \multicolumn{6}{|l|}{ Demographic } \\
\hline Age & $\begin{array}{c}1=16-20 ; 2=21-29 ; 8= \\
80+\end{array}$ & $2.1 \%$ & 0.88 * & 0.84 * & 5 \\
\hline Male (vs. not male) & $1=$ true; $0=$ false & $2.1 \%$ & 0.93 & & \\
\hline White (vs. not white) & $1=$ true $; 0=$ false & $9.1 \%$ & 0.95 & & \\
\hline Bachelor's degree (vs. postgraduate degree) & $1=$ true $; 0=$ false & $2.1 \%$ & 0.94 & & \\
\hline Associates degree or other (vs. postgrad.) & $1=$ true $; 0=$ false & $2.1 \%$ & 0.81 & & \\
\hline \multicolumn{6}{|l|}{ Household } \\
\hline Household income & $1-11$ (\$50 k increments) & $11.8 \%$ & 0.97 & & \\
\hline Number of people in household & $1=$ one $; \ldots 9=$ nine + & $1.5 \%$ & 1.03 & & \\
\hline Number of cars in household & $1=$ one $; \ldots 4=$ four + & $1.5 \%$ & 0.97 & & \\
\hline Replaced a household vehicle (vs. added) & $1=$ true $; 0=$ false & $0.3 \%$ & 0.91 & & \\
\hline Previously owned 1 EV (vs. have not) & $1=$ true $; 0=$ false & $0.3 \%$ & 0.42 * & & \\
\hline Previously owned 2+ EVs (vs. have not) & $1=$ true $; 0=$ false & $0.3 \%$ & $0.20 *$ & & \\
\hline Own home (vs. renting) & $1=$ true $; 0=$ false & $2.8 \%$ & 1.00 & & \\
\hline
\end{tabular}


Table 5. Cont.

\begin{tabular}{|c|c|c|c|c|c|}
\hline Variable Description & Example Values & Missing & $\begin{array}{l}\text { Initial Full } \\
\text { Model Odds } \\
\text { Ratio }\end{array}$ & $\begin{array}{c}\text { Pars. } \\
\text { Model } \\
\text { Odds Ratio }\end{array}$ & $\begin{array}{l}\text { Dom. } \\
\text { Rank }\end{array}$ \\
\hline Multi-unit dwelling (vs. single-family) & $1=$ true $; 0=$ false & $1.8 \%$ & 0.91 & & \\
\hline Planning to install solar (vs. have solar) & $1=$ true $; 0=$ false & $0.5 \%$ & 1.38 & $1.58 *$ & 3 \\
\hline Not planning to install solar (vs. have solar) & $1=$ true $; 0=$ false & $0.5 \%$ & $1.62 *$ & 1.89 * & 3 \\
\hline Not charging at home (vs. chrging at home) & $1=$ true $; 0=$ false & $1.0 \%$ & 1.08 & & \\
\hline \multicolumn{6}{|l|}{ Regional } \\
\hline Work at home/not working (vs. no WPC) & $1=$ true $; 0=$ false & $1.7 \%$ & 0.93 & & \\
\hline Workplace charging (vs. no wrkpl chrging) & $1=$ true $; 0=$ false & $1.7 \%$ & 0.89 & & \\
\hline Central (vs. Bay Area) & $1=$ true $; 0=$ false & $0 \%$ & 0.88 & & \\
\hline Central Coast (vs. Bay Area) & $1=$ true $; 0=$ false & $0 \%$ & 1.19 & & \\
\hline Far South (vs. Bay Area) & $1=$ true $; 0=$ false & $0 \%$ & 0.99 & & \\
\hline North (vs. Bay Area) & $1=$ true $; 0=$ false & $0 \%$ & 0.74 & & \\
\hline South (vs. Bay Area) & $1=$ true $; 0=$ false & $0 \%$ & 0.94 & & \\
\hline Lives in a DAC (vs. outside a DAC) & $1=$ true $; 0=$ false & $0 \%$ & 1.37 & & \\
\hline \multicolumn{6}{|l|}{ Motivational } \\
\hline Enviro impact: Very import (vs. extremely) & $1=$ true $; 0=$ false & $1.2 \%$ & $1.60 *$ & $1.68 *$ & 1 \\
\hline Enviro impact: Mod. import (vs. extremely) & $1=$ true $; 0=$ false & $1.2 \%$ & 2.14 * & $2.25 *$ & 1 \\
\hline Enviro impact: Slightly import (vs. extrmly) & $1=$ true $; 0=$ false & $1.2 \%$ & 1.71 & $1.64 *$ & 1 \\
\hline Enviro impact: Not at all imprt (vs. extrmly) & $1=$ true $; 0=$ false & $1.2 \%$ & 1.83 & $2.01 *$ & 1 \\
\hline Import. of increasing energy independence & $\begin{array}{c}1=\text { not at all, } 5= \\
\text { extremely }\end{array}$ & $1.6 \%$ & 0.95 & & \\
\hline Importance of convenience of charging & $\begin{array}{c}1=\text { not at all; } 5= \\
\text { extremely }\end{array}$ & $1.5 \%$ & 1.03 & & \\
\hline Importance of access to carpool/HOV lane & $\begin{array}{c}1=\text { not at all; } 5= \\
\text { extremely }\end{array}$ & $1.5 \%$ & $0.90 *$ & $0.87 *$ & 6 \\
\hline Importance of saving money on fuel & $\begin{array}{c}1=\text { not at all, } 5= \\
\text { extremely }\end{array}$ & $1.8 \%$ & 1.11 & 1.13 * & 7 \\
\hline Importance of vehicle style & $\begin{array}{c}1=\text { not at all, } 5= \\
\text { extremely }\end{array}$ & $1.5 \%$ & 0.93 & & \\
\hline Importance of vehicle performance & 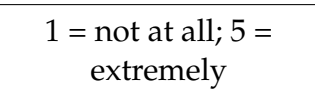 & $1.8 \%$ & 1.05 & & \\
\hline \# of reasons that pulled to acquire a PEV & $\begin{array}{l}0=\text { no reasons; } \ldots 5= \\
\text { five }\end{array}$ & $6.3 \%$ & 1.03 & & \\
\hline 1 reason that pushed to acquire (vs. none) & $1=$ true $; 0=$ false & $6.3 \%$ & 1.26 & & \\
\hline $2+$ reasons that pushed to acquire (vs. none) & $1=$ true $; 0=$ false & $6.3 \%$ & 1.13 & & \\
\hline \multicolumn{6}{|l|}{ Transactional } \\
\hline Time researching: $<4$ h (vs. no time) & $1=$ true $; 0=$ false & $0.7 \%$ & $0.57 *$ & $0.62 *$ & 4 \\
\hline Time researching: 4-12 h (vs. no time) & $1=$ true $; 0=$ false & $0.7 \%$ & $0.45 *$ & $0.52 *$ & 4 \\
\hline Time researching: >12 h (vs. no time) & $1=$ true $; 0=$ false & $0.7 \%$ & $0.41 *$ & $0.47^{*}$ & 4 \\
\hline Heard about CVRP from dealer (vs. elsewh) & $1=$ true $; 0=$ false & $0.8 \%$ & 1.11 & & \\
\hline Rebate Essential (vs. not Rebate Essential) & $1=$ true $; 0=$ false & $1.4 \%$ & 1.21 & & \\
\hline Increased rebate (vs. standard rebate) & $1=$ true $; 0=$ false & $0 \%$ & 1.02 & & \\
\hline Purchase price & $\$ 21,627-\$ 50,835$ & $0 \%$ & 1 & & \\
\hline Purchased vehicle (vs. leased) & $1=$ true $; 0=$ false & $0 \%$ & 0.94 & & \\
\hline Purchase date & $\begin{array}{c}1 \text { November } 2016-31 \\
\text { May } 2017\end{array}$ & $0 \%$ & 1.00 & & \\
\hline Toyota (vs. Chevrolet) & $1=$ true $; 0=$ false & $0 \%$ & $1.53 *$ & $1.60 *$ & 2 \\
\hline Other makes (vs. Chevrolet) & $1=$ true $; 0=$ false & $0 \%$ & $1.99 *$ & $2.07 *$ & 2 \\
\hline
\end{tabular}

* Significance is tested to the $95 \%$ level $(p<0.05)$ and indicated by an asterisk and cell shading. Variables with $p<0.10$ have no asterisk but are lightly shaded. Full model compared to null model via likelihood ratio test: $\mathrm{X}^{2}=4.7, p=0.0000$. Parsimonious model compared to full model via likelihood ratio test: $\mathrm{X}^{2}=2.2, p=0.0001$. 
Table 6. BEV Variables and Model Results.

\begin{tabular}{|c|c|c|c|c|c|}
\hline Variable Description & Example Values & Missing & $\begin{array}{c}\text { Initial Full } \\
\text { Model Odds } \\
\text { Ratio }\end{array}$ & $\begin{array}{c}\text { Pars. } \\
\text { Model } \\
\text { Odds Ratio }\end{array}$ & $\begin{array}{l}\text { Dom. } \\
\text { Rank }\end{array}$ \\
\hline (Intercept) & & & 0.02 & 0.79 & \\
\hline \multicolumn{6}{|l|}{ Demographic } \\
\hline Age & $\begin{array}{c}1=16-20 ; 2=21-29 ; 8= \\
80+\end{array}$ & $1.7 \%$ & $0.84 *$ & $0.80 *$ & 5 \\
\hline Male (vs. not male) & $1=$ true; $0=$ false & $2.2 \%$ & $0.79 *$ & $0.77^{*}$ & 13 \\
\hline White (vs. not white) & $1=$ true $; 0=$ false & $9.4 \%$ & $0.67^{*}$ & $0.68 *$ & 9 \\
\hline Bachelor's degree (vs. postgraduate degree) & $1=$ true $; 0=$ false & $1.7 \%$ & 0.97 & & \\
\hline Associates degree or other (vs. postgrad.) & $1=$ true $; 0=$ false & $1.7 \%$ & 0.99 & & \\
\hline \multicolumn{6}{|l|}{ Household } \\
\hline$\$ 50 \mathrm{k}-\$ 100 \mathrm{k}(\mathrm{vs} .<\$ 50 \mathrm{k})$ & $1=$ true $; 0=$ false & $12.0 \%$ & $0.62 *$ & $0.67^{*}$ & 6 \\
\hline$\$ 100 \mathrm{k}-\$ 150 \mathrm{k}(\mathrm{vs} .<\$ 50 \mathrm{k})$ & $1=$ true $; 0=$ false & $12.0 \%$ & 0.55 * & $0.60 *$ & 6 \\
\hline$\$ 150 \mathrm{k}-\$ 200 \mathrm{k}($ vs. $<\$ 50 \mathrm{k})$ & $1=$ true $; 0=$ false & $12.0 \%$ & $0.49 *$ & 0.55 * & 6 \\
\hline$\$ 200$ k-\$250 k (vs. <\$50 k) & $1=$ true $; 0=$ false & $12.0 \%$ & $0.49 *$ & 0.55 * & 6 \\
\hline$\$ 250 \mathrm{k}-\$ 300 \mathrm{k}(\mathrm{vs} .<\$ 50 \mathrm{k})$ & $1=$ true $; 0=$ false & $12.0 \%$ & $0.40 *$ & $0.47 *$ & 6 \\
\hline$\$ 300 \mathrm{k}$ or more (vs. $<\$ 50 \mathrm{k})$ & $1=$ true $; 0=$ false & $12.0 \%$ & 1.10 & 1.26 & 6 \\
\hline Number of people in household & $1=$ one $; \ldots 9=$ nine + & $1.7 \%$ & 1.08 & & \\
\hline Number of cars in household & $1=$ one $; \ldots 4=$ four + & $1.6 \%$ & 0.99 & & \\
\hline Replaced a household vehicle (vs. added) & $1=$ true $; 0=$ false & $0.2 \%$ & 1.05 & & \\
\hline Previously owned 1 EV (vs. have not) & $1=$ true $; 0=$ false & $0.5 \%$ & 0.34 * & & \\
\hline Previously owned 2+ EVs (vs. have not) & $1=$ true $; 0=$ false & $0.5 \%$ & $0.25 *$ & & \\
\hline Own home (vs. renting) & $1=$ true $; 0=$ false & $2.6 \%$ & 1.09 & & \\
\hline Multi-unit dwelling (vs. single-family) & $1=$ true $; 0=$ false & $1.1 \%$ & 1.15 & & \\
\hline Planning to install solar (vs. have solar) & $1=$ true $; 0=$ false & $0.5 \%$ & 1.04 & 1.14 & 8 \\
\hline Not planning to install solar (vs. have solar) & $1=$ true $; 0=$ false & $0.5 \%$ & 1.32 & $1.43^{*}$ & 8 \\
\hline Not charging at home (vs. chrging at home) & $1=$ true $; 0=$ false & $1.1 \%$ & 0.88 & & \\
\hline \multicolumn{6}{|l|}{ Regional } \\
\hline Work at home/not working (vs. no WPC) & $1=$ true $; 0=$ false & $1.2 \%$ & 0.76 & 0.82 & 12 \\
\hline Workplace charging (vs. no wrkpl chrging) & $1=$ true $; 0=$ false & $1.2 \%$ & 0.80 & $0.78^{*}$ & 12 \\
\hline Central (vs. Bay Area) & $1=$ true $; 0=$ false & $0 \%$ & 1.91 * & $1.86^{*}$ & 7 \\
\hline Central Coast (vs. Bay Area) & $1=$ true $; 0=$ false & $0 \%$ & 1.61 & 1.56 & 7 \\
\hline Far South (vs. Bay Area) & $1=$ true $; 0=$ false & $0 \%$ & 0.85 & 0.82 & 7 \\
\hline North (vs. Bay Area) & $1=$ true $; 0=$ false & $0 \%$ & 0.91 & 0.89 & 7 \\
\hline South (vs. Bay Area) & $1=$ true $; 0=$ false & $0 \%$ & $1.43^{*}$ & 1.34 * & 7 \\
\hline Lives in a DAC (vs. outside a DAC) & $1=$ true $; 0=$ false & $0 \%$ & 0.90 & & \\
\hline \multicolumn{6}{|l|}{ Motivational } \\
\hline Enviro. impact: Very import (vs. extremely) & $1=$ true $; 0=$ false & $1.2 \%$ & $1.61^{*}$ & $1.63^{*}$ & 3 \\
\hline Enviro impact: Mod import (vs. extremely) & $1=$ true $; 0=$ false & $1.2 \%$ & $1.98 *$ & $2.01 *$ & 3 \\
\hline Envr impact: Slightly import (vs. extremly) & $1=$ true $; 0=$ false & $1.2 \%$ & 1.80 * & $1.81 *$ & 3 \\
\hline Enviro impact: Not import (vs. extremely) & $1=$ true $; 0=$ false & $1.2 \%$ & $3.61 *$ & $3.39 *$ & 3 \\
\hline Energy indpndnce: Very imprt (vs. extrmly) & $1=$ true $; 0=$ false & $1.6 \%$ & 1.26 & $1.42 *$ & 4 \\
\hline Energy indep: Mod import (vs. extremely) & $1=$ true $; 0=$ false & $1.6 \%$ & 1.33 & $1.44^{*}$ & 4 \\
\hline Energy indep: Slightly import (vs. extrmly) & $1=$ true $; 0=$ false & $1.6 \%$ & 1.28 & 1.51 * & 4 \\
\hline Energy indep: Not important (vs. extrmly) & $1=$ true $; 0=$ false & $1.6 \%$ & 0.57 * & 0.69 & 4 \\
\hline Importance of convenience of charging & $\begin{array}{c}1=\text { not at all } ; \ldots 5= \\
\text { extremely }\end{array}$ & $1.9 \%$ & 0.99 & & \\
\hline Importance of access to carpool/HOV lane & $\begin{array}{c}1=\text { not at all } ; \ldots 5= \\
\text { extremely }\end{array}$ & $1.4 \%$ & 0.97 & $0.92 *$ & 14 \\
\hline Save \$ on fuel: Very import (vs. extrmly) & $1=$ true $; 0=$ false & $1.9 \%$ & 1.24 & & \\
\hline Save \$ on fuel: Mod import (vs. extremely) & $1=$ true $; 0=$ false & $1.9 \%$ & 1.32 & & \\
\hline Save $\$$ on fuel: Slightly import (vs. extrmly) & $1=$ true $; 0=$ false & $1.9 \%$ & 1.47 & & \\
\hline Save $\$$ on fuel: Not import (vs. extremely) & $1=$ true $; 0=$ false & $1.9 \%$ & 1.10 & & \\
\hline
\end{tabular}


Table 6. Cont.

\begin{tabular}{|c|c|c|c|c|c|}
\hline Variable Description & Example Values & Missing & $\begin{array}{c}\text { Initial Full } \\
\text { Model Odds } \\
\text { Ratio }\end{array}$ & $\begin{array}{c}\text { Pars. } \\
\text { Model } \\
\text { Odds Ratio }\end{array}$ & $\begin{array}{l}\text { Dom. } \\
\text { Rank }\end{array}$ \\
\hline Vehicle style: Very important (vs. extremly) & $1=$ true $; 0=$ false & $1.6 \%$ & 1.41 & $1.49^{*}$ & 11 \\
\hline Vehcle style: Mod important (vs. extremely) & $1=$ true $; 0=$ false & $1.6 \%$ & 1.02 & 1.13 & 11 \\
\hline Vehcle style: Slightly import (vs. extremely) & $1=$ true $; 0$ = false & $1.6 \%$ & 1.24 & 1.37 & 11 \\
\hline Vehcle style: Not important (vs. extremely) & $1=$ true $; 0=$ false & $1.6 \%$ & 0.97 & 1.07 & 11 \\
\hline Importance of vehicle performance & $\begin{array}{c}1=\operatorname{not} \text { at all } ; \ldots 5= \\
\text { extremely }\end{array}$ & $1.8 \%$ & 0.93 & & \\
\hline \# of reasons that pulled to acquire a PEV & $\begin{array}{c}0=\text { no reasons; } \ldots 6=6= \\
\text { six }\end{array}$ & $6.4 \%$ & 1.00 & & \\
\hline 1 reason that pushed to acquire (vs. none) & $1=$ true $; 0=$ false & $6.4 \%$ & 1.01 & & \\
\hline 2 reasons that pushed to acquire (vs. none) & $1=$ true $; 0=$ false & $6.4 \%$ & 1.17 & & \\
\hline \multicolumn{6}{|l|}{ Transactional } \\
\hline Time researching: $<4 \mathrm{~h}$ (vs. no time) & $1=$ true $; 0=$ false & $0.7 \%$ & 0.64 * & $0.69 *$ & 1 \\
\hline Time researching: 4-12 h (vs. no time) & $1=$ true $; 0=$ false & $0.7 \%$ & $0.57 *$ & $0.64 *$ & 1 \\
\hline Time researching: $>12 \mathrm{~h}$ (vs. no time) & $1=$ true $; 0$ = false & $0.7 \%$ & 0.25 * & 0.28 * & 1 \\
\hline Heard about CVRP from dealer (vs. elsewh) & $1=$ true $; 0=$ false & $0.9 \%$ & 0.95 & & \\
\hline Rebate Essential (vs. not Rebate Essential) & $1=$ true $; 0=$ false & $1.1 \%$ & $1.27 *$ & $1.28 *$ & 10 \\
\hline Increased rebate (vs. standard rebate) & $1=$ true $; 0=$ false & $0 \%$ & 0.84 & & \\
\hline Purchase price & $\$ 21,180-\$ 165,200$ & $0 \%$ & 1 & & \\
\hline Purchased vehicle (vs. leased) & $1=$ true $; 0=$ false & $0 \%$ & 0.92 & & \\
\hline Purchase date & $\begin{array}{c}1 \text { November 2016-31 } \\
\text { May } 2017\end{array}$ & $0 \%$ & 1.00 & & \\
\hline Tesla (vs. Chevrolet [Bolt]) & $1=$ true $; 0=$ false & $0 \%$ & 0.68 & 1.13 & 2 \\
\hline Other makes (vs. Chevrolet [Bolt]) & $1=$ true $; 0=$ false & $0 \%$ & $1.87^{*}$ & $1.92 *$ & 2 \\
\hline
\end{tabular}

* Significance is tested to the $95 \%$ level $(p<0.05)$ and indicated by an asterisk and cell shading. Variables with $p<0.10$ have no asterisk but are lightly shaded. Full model compared to null model via likelihood ratio test: $\mathrm{X}^{2}=9.8, p=0.0000$. Parsimonious model compared to full model via likelihood ratio test: $X^{2}=4.2, p=0.0000$.

Nonsignificance should not be taken as definitive proof of the unimportance of a predictor, but rather as a failure to detect any significance, if any exists. Regardless, there is no evidence that nonsignificant predictors, such as most PHEV demographics, are related to being an EV Convert. Demographically, it might be expected that PHEV consumers, who tend to resemble mainstream new-car buyers somewhat more than BEV consumers (as seen in various statistics ranging from [35] to the bottom four rows of Table 4), might exhibit less distinction between their "more mainstream segment" (PHEV Converts) and their "adopter population" (PHEV consumers overall).

Many of the model findings reinforce the descriptive statistics. The difference between segment and population in Table 4 tends to be smaller for nonsignificant predictors and larger for significant ones. Interestingly, several of the characteristics not found to significantly increase the odds of being an EV Convert nonetheless appear to be substantively different between population and segment. For example, the percentage of BEV Converts that own their residence $(73 \%)$ is seven percentage points (accounting for rounding in Table 4) lower than the BEV population overall ( $81 \%)$. This highlights how descriptive averages can wash out or obscure complex underlying dynamics, pointing to the value of predictive approaches like logistic regression that better explain segment status.

It is also interesting to note that many household, charging, and financial factors are not the basis for identifying who might be converted into EV adoption, with the exception of BEV consumer income and Rebate Essentiality. Nor are vehicle performance (for both BEV and PHEV consumers) and vehicle style (PHEV consumers only) predictors. (The results of a Tesla-only model might be different.) Finally, although saving money on fuel 
has long been a highly rated EV purchase/lease motivation [12], it might not be quite as important if specifically trying to convert recent low-interest shoppers into BEV consumers.

\subsection{Dominance Ranking Results and Discussion}

Dominance analysis is used to understand the relative importance of significant variables. Variables can be rank ordered by general dominance, in this case as measured by average contribution to the model using Estrella pseudo- $\mathrm{R}^{2}$ [48]. When dominance analysis is applied to linear regression, $\mathrm{R}^{2}$ is typically used to measure predictor contribution to the model. $\mathrm{R}^{2}$ is not obtainable from a logistic regression, so pseudo- $\mathrm{R}^{2}$ is used instead. Estrella's pseudo- $R^{2}$ ranges between 0 and 1 and can be interpreted similarly to $R^{2}$. (Azen and Traxel found no practical differences between using McFadden's, Estrella's or Nagelkerke's pseudo- $\mathrm{R}^{2}$, and recommended McFadden's or Estrella's for use in dominance analyses [47].) Tables 7 and 8 rank the average contribution of predictors for the Parsimonious PHEV and BEV Models, respectively. Because the average of average contribution values represent contributions to pseudo- $\mathrm{R}^{2}$, the values appear quite small relative to what one might expect for a model's overall pseudo- $\mathrm{R}^{2}$. Average of average contributions ranged from 0.0019 to 0.0175 for PHEV, and 0.0024 to 0.0335 for BEV. Elements common to both models are colored dark orange, following Figure 1.

Table 7. Summary and Rank-Ordering of Key PHEV Convert Predictors (Dominance Analysis).

\begin{tabular}{cccc}
\hline Variable Description & $\begin{array}{c}\text { Odds-Increasing Examples } \\
\text { [See Table 5] }\end{array}$ & $\begin{array}{c}\text { Average of Pseudo-R } \\
\text { Average Contributions }\end{array}$ & Rank \\
\hline $\begin{array}{c}\text { Reducing enviro. } \\
\text { impacts }\end{array}$ & Moderately or not important & 0.0175 & 1 \\
\hline Vehicle make & Not Chevy (Volt) & 0.0162 & 2 \\
\hline Solar & No solar & 0.0112 & 3 \\
\hline Time researching EVs & None or fewer hours & 0.0094 & 4 \\
\hline Age & Younger & 0.0085 & 5 \\
\hline Carpool/HOV access & Less important & 0.0033 & 6 \\
\hline Saving money on fuel & More important & 0.0019 & 7 \\
\hline
\end{tabular}

Table 8. Summary and Rank-Ordering of Key BEV Convert Predictors (Dominance Analysis).

\begin{tabular}{cccc}
\hline Variable Description & $\begin{array}{c}\text { Odds-Increasing Example } \\
\text { [See Table 6] }\end{array}$ & $\begin{array}{c}\text { Average of Pseudo-R } \\
\text { Average Contributions }\end{array}$ & Rank \\
\hline Time researching EVs & None or fewer hours & 0.0335 & 1 \\
\hline $\begin{array}{c}\text { Vehicle make } \\
\text { impacts }\end{array}$ & Not Chevy (Bolt) & 0.0211 & 3 \\
\hline Enederately or not important & 0.0189 & 4 \\
\hline Andependence & Moderately important & 0.0140 & 5 \\
\hline Income & Younger & 0.0134 & 6 \\
\hline Region & Lower & 0.0129 & 7 \\
\hline Solar & Central CA or LA (vs. Bay & 0.0125 & 8 \\
\hline Race / ethnicity & Not planning to install & 0.0081 & 9 \\
\hline
\end{tabular}


Table 8. Cont.

\begin{tabular}{cccc}
\hline Variable Description & $\begin{array}{c}\text { Odds-Increasing Example } \\
\text { [See Table 6] }\end{array}$ & $\begin{array}{c}\text { Average of Pseudo-R } \\
\text { Average Contributions }\end{array}$ & Rank \\
\hline Vehicle style & $\begin{array}{c}\text { Very/less-than-extremely } \\
\text { important }\end{array}$ & 0.0047 & 11 \\
\hline Workplace charging & No workplace charging & 0.0038 & 12 \\
\hline Gender & Not male & 0.0037 & 13 \\
\hline $\begin{array}{c}\text { Carpool/HOV lane } \\
\text { access }\end{array}$ & Less important & 0.0024 & 14 \\
\hline
\end{tabular}

Only two characteristics are unique to PHEV Converts that do not also increase the odds of being a BEV Convert. One is a higher importance given to saving money on fuel, a factor that is important to BEV consumers in general but does not appear to distinguish the BEV Convert segment. Even for PHEV consumers, this factor is ranked 7th out of 7 significant factors. The second is that, although neither PHEV nor BEV Converts tend to have solar, the odds of being in the PHEV segment may also be increased somewhat if the consumer does not have solar but is planning to install it. This is perhaps a minor distinction, but not having solar overall is ranked third, and it contributes an order of magnitude more to the model than the importance of saving money on fuel.

Several significant predictors are unique to BEV Converts. The lower the importance of energy independence, the greater the odds of being in the segment (\#4 in Table 8), although it is unclear if the issue can be of no importance (Table 6). It is possible that predictors like this measure factors that "pre-convert" consumers before they begin their vehicle search; the greater the importance of an issue, the less likely the consumer has little or no initial interest in a product that addresses that issue. Others that might also be "pre-converters" include giving importance to reducing environmental impacts (\#3) and carpool-lane access (\#14), as well as having workplace charging (\#12) and spending time researching EVs (\#1). EV adopters in general rate environmental impacts, carpool-lane access, and energy independence as highly important reasons [12,28]. This reinforces the idea that $E V$ Converts are a step on the way toward more mainstream consumers. Many other financial aspects do not increase the odds of EV Convert status, but lower household income (\#6) and Rebate Essentiality (\#10) do for BEV consumers. As such, rebates might be thought of as "potential converters." Like findings from Rebate Essential segmentation [23,24], region (\#7) plays an important role in increasing the odds for BEV consumers. Discussion about region in that research may apply here as well. Further down the list of BEV-unique predictors, the contribution diminishes. However, it is interesting to note that this BEV population is more mainstream than the PHEV population when it comes to race/ethnicity (\#9) measures. Further, the BEV Convert segment is not only partly explained by race/ethnicity, the segment actually appears less frequently white than even the new-car buyer population as a whole. Similarly, the segment appears somewhat less frequently male than the BEV population-although still somewhat more frequently male than new-car buyers. Perhaps confounded by the mix of Tesla and non-Tesla BEVs in the population, the odds of segment status are increased by rating vehicle style less than extremely important, but only "very important" is significant.

Nearly all the predictors that increase the odds of being a PHEV Convert also increase the odds of being a BEV Convert. Time spent researching EVs is an intuitive "pre-converter." Spending few or no hours doing so moderately contributes to the explanation of PHEV Converts (\#3) and greatly contributes to the explanation of BEV Converts (\#1). However, it would be interesting to see the results of subsequent modelling that does not include this variable. Vehicle make is another common predictor that tends to be important in this and other segmentation efforts [23], ranking \#2 for both technology types. Make has proven difficult to operationalize in programs that do not wish to provide preferential attention to dealerships selling certain vehicle brands, and it may also be revealing to 
remove make in subsequent modelling. However, as with region, make may be acting as a collector of a variety of unmodelled predictors. The moderate importance or unimportance of reducing environmental impacts to both PHEV Converts (\#1) and BEV Converts (\#3) is perhaps the most prominent and potentially actionable finding. This is consistent with findings that environmental impacts have not ranked highly in most car buying decisionmaking specifically, even in international contexts that have higher willingness-to-pay for reducing environmental impacts in general than the U.S. [50]. As described previously, however, it should be kept in mind that current EV adopters as a whole tend to rank these factors highly. This highlights the unique place in the market that EV Converts occupy in the overlap between enthusiastic EV early adopters and mainstream consumers: they are among the earlier actual adopters of EVs but do not share the environmental motivations of the typical more EV-enthusiastic adopter. This also highlights that a choice needs to be made about how far afield from current adopters targeting strategies should aim.

Similarly, Section 3.1. used the example of the "younger age" finding (\#5 for both PHEV and BEV consumers) to highlight the relative and absolute distributions of age: EV Converts trend younger than typical EV adopters, but may or may not be significantly younger than baselines characterizing new-car buyers as a whole. Not having solar with no plans to install it (\#3 for PHEV consumers and \#8 for BEV consumers) is a significant departure from strategies aimed to reinforce and scale existing adoption, because solar ownership may be on the order of two to three times more common amongst EV owners [12]. Finally, giving less importance to carpool-lane access (\#6 for PHEV consumers and \#14 for BEV consumers) was discussed above.

Previous examinations of EV Converts used the 2013-15 Edition of the CVRP Consumer Survey [22,26]. Modelling differences exist between the two efforts, but assuming they are roughly comparable, what differences might time and program-design changes have produced? Over time, both PHEV and BEV segments remain associated with a lack of solar, spending less time researching EVs online, and being less motivated by environmental impacts and carpool-lane access. Both segments are now associated with younger age. Additionally, the PHEV segment is no longer associated with race/ethnicity, energy independence, hearing about the rebate from the dealer, rebate influence, and buying (vs. leasing). College degrees, household size, being motivated by fuel cost savings and vehicle performance, and vehicle replacement no longer help explain the BEV segment, whereas female gender and income are now also associated. Non-white race/ethnicity, lack of workplace charging, residence in central California, and being Rebate Essential also continue to help explain the BEV segment.

\section{Conclusions, Caveats, and the Path Forward}

How can electric-vehicle markets move beyond enthusiasts and further into the mainstream? This research explores a market segment in the overlap between existing EV adoption and more conventional consumers that might help point the way: EV consumers with low or no initial interest in EVs, or "EV Converts." About one-fifth of PHEV consumers and one-quarter of BEV consumers in a rebate dataset that characterizes over half of the recent EV market in California (Table 1) are categorized as EV Converts (Figure 1). Summarized descriptively (Table 4), key demographic characteristics of PHEV and $B E V$ Convert segments tend to fall between their respective EV populations and new-vehicle buyers overall. PHEV Converts somewhat more closely resemble new-car buyers on more of the characteristics provided, but BEV Converts actually "go beyond" mainstream markets on two measures: they appear to be younger and less frequently white/Caucasian than new-car buyers, on average.

Many household, charging, and financial factors, as well as vehicle performance, were not found to be the basis for explaining who might be converted into EV adoption (Section 3.2). Additionally, although saving money on fuel has long been a highly rated EV purchase/lease motivation [28] and was significant in earlier analysis of EV Converts using 2013-15 data (Section 3.3), it was not found to be significant for the BEV Convert segment 
in the 2016-17 data. Saving money on fuel therefore might not be quite as important if specifically trying to convert low-interest shoppers into BEV consumers at this stage in the market's evolution. This is an intriguing finding particularly because income was controlled for as part of the modelling.

Further, the BEV Convert segment examined herein has a lower percentage of members with household incomes over $\$ 100,000$ per year than the BEV rebated-consumer population as a whole, per Table 4 . Because the importance of saving money on fuel no longer helps explain $B E V$ Convert status specifically, additional investigation might wish to examine if this is an indicator of a more general change happening within the population BEV consumers overall with broader implications for marketing BEV products.

Tables 7 and 8 provide the key results for moving forward. They rank-order the significant characteristics by their contribution to explaining PHEV and BEV Converts, respectively. Nearly all the predictors that increase the odds of being a PHEV Convert also increase the odds of being a BEV Convert. These common predictors represent win-win factors for strategies to target adopters of both products, albeit with differing importance for each technology type. Relative to "high" values for EV adopters overall, EV Converts tend to have "lower" values on factors that might have otherwise "pre-converted" them to EV interest: few or no hours spent researching EVs online; less or no motivation derived from environmental impacts, energy independence, and carpool-lane access; and no solar. Except for energy independence, these findings are consistent with examination of 2013-15-era survey data, before California's rebate program included an income cap and Increased Rebate for lower-income consumers. Lack of workplace charging also continues to be associated with $B E V$ Convert status. Both groups of $E V$ Converts are now also associated with younger consumers, perhaps less established in their car-buying and/or more receptive to EVs in the end. The odds of being a BEV Convert, as well as the odds of being Rebate Essential [24], are also increased by residence in California's more rural and conservative Central Valley and its diverse greater-LA Southern California region (relative to the EV-rich San Francisco Bay Area). Region may be acting like a consumer's milieu and a catch-all for a variety of unmeasured factors [24] relating to relatively higher levels of: EVs, EV-awareness, successful EV-supportive policies and infrastructure, and/or other pre-converters in the Bay Area. Predictors that not only help target, but also help convert, consumers include rebates for BEV consumers and (possibly with modest impact) the promise of fuel-cost savings for PHEV consumers.

Caveats. Although based upon large datasets characterizing major portions of California's nation-leading EV market, this work is first and foremost applicable to efforts to optimize CVRP and related programs to grow and diversify California's EV market. Analyses using similar rebate-program datasets from three Northeastern U.S. states (Massachusetts, Connecticut, and New York) have tended to show more commonalities across states than differences, at least to-date using relatively aggregated measures of program participation and impact [51]. However, interpretation should be done with caution and mindful of CVRP's program features and California's unique market. Extrapolation of these results to international contexts must be done with even more caution, as factors related to country-specific car-owning, EV-market, and policy environments could eclipse any commonalities that might exist across early adopters and their approach maturing EV products. (However, the method utilized here to identify and rank-order characteristics associated with being in a strategic segment like EV Converts should be universally applicable, subject to data-availability limitations.) Further, the uniqueness and recent dominance of Tesla in the market warrants separate modelling of Tesla and non-Tesla BEV groups. It should also be noted that $E V$ Converts are not the only, or necessarily even the highest-priority, strategic segment—goals and priorities vary. Converts support the goal of "mainstreaming," but other segments support the overlapping but distinct goals of direct market acceleration (scaling existing adoption), cost-effectiveness (Rebate Essentials), and equity (priority populations) [22,52,53]. State-specific and Tesla-specific EV Convert analysis, as well as similar market segmentation exercises for Rebate Essentials and priority 
populations, are planned next steps. Finally, analysis of program non-participants is critical to understanding key barriers to market entry that may be standing in the way of "potential converts."

Nevertheless, it is hoped the results presented here can help increase EV adoption broadly in three ways: targeting for expansion, converting, and pre-converting. The primary focus here has been targeting for expansion: profiling a strategic segment of consumers who have successfully adopted EVs but who are also more mainstream in character, and then targeting folks with similar characteristics to "go get more" and encourage them to join the EV market. Targeting can be achieved through both outreach that proactively seeks out these "potential converts," or through incentive design that is mindful of them. The second way these results can help is by confirming the significance of direct "converters" - like rebates for BEV Converts and the promise of fuel-cost savings for PHEV Converts. Finally, an indirect way to use these results is to examine the factors that may have "pre-converted" consumers, in order to reinforce those and avoid the need for conversion by increasing interest. This can be done through: examination of notable nonsignificant factors, through significant findings (e.g., lack of workplace charging as a missed opportunity to pre-convert BEV consumers), or through further investigation into "catch-all" predictors like vehicle make and residence region. They all provide clues about the differences between consumers with initial interest in EVs and those who do not acquire that interest until later in their vehicle purchase/lease consideration process. All told, it is hoped that this work will help resources effectively find, and support the growth of, a margin of overlap between what is already working in the EV market and where we might desire the EV market to be: beyond enthusiastic early adopters and further into the mainstream.

Author Contributions: B.D.H.W.: Conceptualization, Methodology, Validation, Investigation, Resources, Data Curation, Writing-Original, Writing—Review and Editing, Visualization, Supervision, Project administration, Funding acquisition. J.B.A.: Methodology, Software, Validation, Formal analysis, Investigation, Data Curation, Writing-Original Draft, Writing—Review and Editing, Visualization, Supervision. Both authors have read and agreed to the published version of the manuscript.

Funding: This research was funded by a grant for the administration of the Clean Vehicle Rebate Project, a program of the California Air Resources Board (G17-CVRP-01 and G18-CVRP-01). The funders were not involved in the conduct of the research.

Institutional Review Board Statement: Not applicable.

Informed Consent Statement: Program participants agreed to the collection and anonymized use of data as a term and condition of program participation.

Data Availability Statement: Data analyzed for this study were collected as part of the administration of the Clean Vehicle Rebate Project and are not available in raw form to protect participant confidentiality and sensitive information. However, portions of the data are available for free download via program dashboards, as are a variety of analyses that shed additional light on its collection and qualities: http:/ / cleanvehiclerebate.org (accessed 25 February 2021). Particularly relevant examples can be found in the references herein. Finally, the data inputs for two tables and one figure in this work are available in an online repository here: https:/ / doi.org/10.17632/vdvxptxyfj.2 (accessed 25 February 2021).

Acknowledgments: This work was conducted to inform the Clean Vehicle Rebate Project and support efforts to strategically commercialize clean-vehicle technology. The authors thank the CARB staff who manage CVRP. Additional thanks are due to Jennifer Boughton for new-vehicle buyer calculations, Keir Havel for analytical support, James Tamerius for feedback, and others at CSE who supported this work. In particular, the authors are indebted to the prior work of Clair Johnson. However, the opinions, conclusions, and mistakes herein are those of the authors.

Conflicts of Interest: The authors declare that they have no known competing financial interests or personal relationships that could have appeared to influence the work reported in this paper. The funders were not involved in the conduct of the research. 


\section{Appendix A}

Table A1. Ordinal and Categorical Variable Data Summary.

\begin{tabular}{|c|c|c|c|c|c|c|c|c|}
\hline & \multicolumn{4}{|c|}{ PHEV } & \multicolumn{4}{|c|}{ BEV } \\
\hline & Missing & Frequency & $\begin{array}{l}\text { Valid } \\
\text { Pct. }\end{array}$ & $\begin{array}{c}\text { Wghtd } \\
\text { Valid Pct. }\end{array}$ & Missing & Frequency & $\begin{array}{l}\text { Valid } \\
\text { Pct. }\end{array}$ & $\begin{array}{c}\text { Wghtd } \\
\text { Valid Pct. }\end{array}$ \\
\hline \multicolumn{9}{|l|}{ Demographics } \\
\hline Age & $2.0 \%$ & 2230 & & & $1.7 \%$ & 3118 & & \\
\hline $16-20$ & & 3 & $0.1 \%$ & $0.2 \%$ & & 4 & $0.1 \%$ & $0.2 \%$ \\
\hline $21-29$ & & 118 & $5.3 \%$ & $5.8 \%$ & & 132 & $4.2 \%$ & $4.6 \%$ \\
\hline $30-39$ & & 380 & $17.0 \%$ & $18.0 \%$ & & 602 & $19.3 \%$ & $20.6 \%$ \\
\hline $40-49$ & & 491 & $22.0 \%$ & $22.9 \%$ & & 828 & $26.6 \%$ & $27.2 \%$ \\
\hline $50-59$ & & 561 & $25.2 \%$ & $25.0 \%$ & & 761 & $24.4 \%$ & $24.2 \%$ \\
\hline $60-69$ & & 440 & $19.7 \%$ & $18.4 \%$ & & 546 & $17.5 \%$ & $16.2 \%$ \\
\hline $70-79$ & & 198 & $8.9 \%$ & $8.3 \%$ & & 207 & $6.6 \%$ & $6.0 \%$ \\
\hline $80+$ & & 39 & $1.7 \%$ & $1.5 \%$ & & 38 & $1.2 \%$ & $1.1 \%$ \\
\hline Gender & $2.0 \%$ & 2230 & & & $2.2 \%$ & 3101 & & \\
\hline Female & & 673 & $30.2 \%$ & $29.5 \%$ & & 834 & $26.9 \%$ & $27.2 \%$ \\
\hline Male & & 1557 & $69.8 \%$ & $70.5 \%$ & & 2267 & $73.1 \%$ & $72.8 \%$ \\
\hline Race/ethnicity & $9.0 \%$ & 2071 & & & $9.4 \%$ & 2873 & & \\
\hline Other races or ethnicities & & 800 & $38.6 \%$ & $40.1 \%$ & & 1149 & $40.0 \%$ & $42.9 \%$ \\
\hline White or Caucasian & & 1271 & $61.4 \%$ & $59.9 \%$ & & 1724 & $60.0 \%$ & $57.1 \%$ \\
\hline Highest household education level & $2.1 \%$ & 2229 & & & $1.6 \%$ & 3119 & & \\
\hline Post-graduate degree & & 957 & $42.9 \%$ & $42.3 \%$ & & 1532 & $49.1 \%$ & $48.6 \%$ \\
\hline Bachelor's degree & & 778 & $34.9 \%$ & $35.3 \%$ & & 1068 & $34.2 \%$ & $34.4 \%$ \\
\hline Some college or other education & & 494 & $22.2 \%$ & $22.4 \%$ & & 519 & $16.6 \%$ & $17.0 \%$ \\
\hline \multicolumn{9}{|l|}{ Household } \\
\hline Household Income & $11.7 \%$ & 2009 & & & $12.0 \%$ & 2792 & & \\
\hline Less than $\$ 50,000$ & & 215 & $10.7 \%$ & $11.0 \%$ & & 279 & $10.0 \%$ & $10.7 \%$ \\
\hline$\$ 50,000-\$ 99,999$ & & 506 & $25.2 \%$ & $24.8 \%$ & & 516 & $18.5 \%$ & $18.3 \%$ \\
\hline$\$ 100,000-\$ 149,999$ & & 609 & $30.3 \%$ & $29.8 \%$ & & 772 & $27.7 \%$ & $27.5 \%$ \\
\hline$\$ 150,000-\$ 199,999$ & & 356 & $17.7 \%$ & $17.6 \%$ & & 569 & $20.4 \%$ & $20.4 \%$ \\
\hline$\$ 200,000-\$ 249,999$ & & 209 & $10.4 \%$ & $10.7 \%$ & & 387 & $13.9 \%$ & $13.7 \%$ \\
\hline$\$ 250,000-\$ 299,999$ & & 80 & $4.0 \%$ & $4.3 \%$ & & 200 & $7.2 \%$ & $7.1 \%$ \\
\hline$\$ 300,000-\$ 349,999$ & & 24 & $1.2 \%$ & $1.3 \%$ & & 44 & $1.6 \%$ & $1.5 \%$ \\
\hline$\$ 350,000-\$ 399,999$ & & 7 & $0.3 \%$ & $0.4 \%$ & & 13 & $0.5 \%$ & $0.5 \%$ \\
\hline$\$ 400,000-\$ 449,999$ & & 1 & $\sim 0.0 \%$ & $0.1 \%$ & & 3 & $0.1 \%$ & $0.1 \%$ \\
\hline$\$ 450,000-\$ 499,999$ & & 0 & $0.0 \%$ & $0.0 \%$ & & 1 & $\sim 0.0 \%$ & $\sim 0.0 \%$ \\
\hline$\$ 500,000$ or more & & 2 & $0.1 \%$ & $0.1 \%$ & & 8 & $0.3 \%$ & $0.3 \%$ \\
\hline Number of people in household & $1.2 \%$ & 2249 & & & $1.2 \%$ & 3133 & & \\
\hline 1 & & 242 & $10.8 \%$ & $10.6 \%$ & & 272 & $8.7 \%$ & $8.4 \%$ \\
\hline 2 & & 956 & $42.5 \%$ & $40.4 \%$ & & 1177 & $37.6 \%$ & $36.2 \%$ \\
\hline 3 & & 398 & $17.7 \%$ & $18.1 \%$ & & 629 & $20.1 \%$ & $20.3 \%$ \\
\hline 4 & & 479 & $21.3 \%$ & $22.8 \%$ & & 737 & $23.5 \%$ & $24.4 \%$ \\
\hline
\end{tabular}


Table A1. Cont.

\begin{tabular}{|c|c|c|c|c|c|c|c|c|}
\hline & \multicolumn{4}{|c|}{ PHEV } & \multicolumn{4}{|c|}{ BEV } \\
\hline & Missing & Frequency & $\begin{array}{l}\text { Valid } \\
\text { Pct. }\end{array}$ & $\begin{array}{c}\text { Wghtd } \\
\text { Valid Pct. }\end{array}$ & Missing & Frequency & $\begin{array}{l}\text { Valid } \\
\text { Pct. }\end{array}$ & $\begin{array}{c}\text { Wghtd } \\
\text { Valid Pct. }\end{array}$ \\
\hline 5 & & 114 & $5.1 \%$ & $5.4 \%$ & & 222 & $7.1 \%$ & $7.5 \%$ \\
\hline 6 & & 45 & $2.0 \%$ & $2.0 \%$ & & 65 & $2.1 \%$ & $2.2 \%$ \\
\hline 7 & & 10 & $0.4 \%$ & $0.4 \%$ & & 24 & $0.8 \%$ & $0.8 \%$ \\
\hline 8 & & 4 & $0.2 \%$ & $0.2 \%$ & & 4 & $0.1 \%$ & $0.1 \%$ \\
\hline 9 or more & & 1 & $\sim 0.0 \%$ & $\sim 0.0 \%$ & & 3 & $0.1 \%$ & $0.1 \%$ \\
\hline Number of cars in household & $1.3 \%$ & 2246 & & & $1.4 \%$ & 3126 & & \\
\hline 1 & & 391 & $17.4 \%$ & $17.5 \%$ & & 390 & $12.5 \%$ & $12.3 \%$ \\
\hline 2 & & 1032 & $45.9 \%$ & $45.9 \%$ & & 1476 & $47.2 \%$ & $47.2 \%$ \\
\hline 3 & & 554 & $24.7 \%$ & $24.7 \%$ & & 838 & $26.8 \%$ & $26.8 \%$ \\
\hline 4 or more & & 269 & $12.0 \%$ & $11.9 \%$ & & 422 & $13.5 \%$ & $13.6 \%$ \\
\hline Replacement or Additional Vehicle & $0.0 \%$ & 2276 & & & $0.0 \%$ & 3171 & & \\
\hline Additional & & 313 & $13.8 \%$ & $13.7 \%$ & & 756 & $23.8 \%$ & $25.3 \%$ \\
\hline Replacement & & 1963 & $86.2 \%$ & $86.3 \%$ & & 2415 & $76.2 \%$ & $74.7 \%$ \\
\hline Number of previous EVs owned & $0.0 \%$ & 2276 & & & $0.0 \%$ & 3171 & & \\
\hline 0 & & 1651 & $72.5 \%$ & $70.7 \%$ & & 2104 & $66.4 \%$ & $66.5 \%$ \\
\hline 1 & & 494 & $21.7 \%$ & $23.3 \%$ & & 851 & $26.8 \%$ & $27.2 \%$ \\
\hline 2 or more & & 131 & $5.8 \%$ & $6.1 \%$ & & 216 & $6.8 \%$ & $6.3 \%$ \\
\hline Own or rent residence & $2.8 \%$ & 2212 & & & $2.6 \%$ & 3090 & & \\
\hline Rent & & 495 & $22.4 \%$ & $23.9 \%$ & & 552 & $17.9 \%$ & $19.4 \%$ \\
\hline Own & & 1717 & $77.6 \%$ & $76.1 \%$ & & 2538 & $82.1 \%$ & $80.6 \%$ \\
\hline Residence Type & $1.6 \%$ & 2239 & & & $1.1 \%$ & 3135 & & \\
\hline Detached house & & 1710 & $76.4 \%$ & $75.3 \%$ & & 2494 & $79.6 \%$ & $78.2 \%$ \\
\hline $\begin{array}{c}\text { Attached house, apartment or } \\
\text { condo }\end{array}$ & & 529 & $23.6 \%$ & $24.7 \%$ & & 641 & $20.4 \%$ & $21.8 \%$ \\
\hline Solar on residence & $0.0 \%$ & 2276 & & & $0.0 \%$ & 3171 & & \\
\hline Yes & & 475 & $20.9 \%$ & $19.7 \%$ & & 862 & $27.2 \%$ & $24.9 \%$ \\
\hline $\begin{array}{l}\text { No, but I am planning to install } \\
\text { solar panels within the next } \\
\text { year }\end{array}$ & & 309 & $13.6 \%$ & $13.8 \%$ & & 501 & $15.8 \%$ & $15.4 \%$ \\
\hline $\begin{array}{l}\text { No, I am not planning to or am } \\
\text { not able to install solar }\end{array}$ & & 1492 & $65.6 \%$ & $66.5 \%$ & & 1808 & $57.0 \%$ & $59.7 \%$ \\
\hline Not charging at home & $0.7 \%$ & 2260 & & & $0.8 \%$ & 3146 & & \\
\hline Charging at home & & 1989 & $88.0 \%$ & $87.1 \%$ & & 2760 & $87.7 \%$ & $87.0 \%$ \\
\hline Not charging at home & & 271 & $12.0 \%$ & $12.9 \%$ & & 386 & $12.3 \%$ & $13.0 \%$ \\
\hline \multicolumn{9}{|l|}{ Regional } \\
\hline Access to workplace charging & $1.2 \%$ & 2248 & & & $0.7 \%$ & 3149 & & \\
\hline No or not sure & & 860 & $38.3 \%$ & $37.9 \%$ & & 1022 & $32.5 \%$ & $32.4 \%$ \\
\hline $\begin{array}{l}\text { Work from home or not } \\
\text { applicable }\end{array}$ & & 463 & $20.6 \%$ & $19.5 \%$ & & 627 & $19.9 \%$ & $18.4 \%$ \\
\hline Yes & & 925 & $41.1 \%$ & $42.5 \%$ & & 1500 & $47.6 \%$ & $49.2 \%$ \\
\hline
\end{tabular}


Table A1. Cont.

\begin{tabular}{|c|c|c|c|c|c|c|c|c|}
\hline & \multicolumn{4}{|c|}{ PHEV } & \multicolumn{4}{|c|}{ BEV } \\
\hline & Missing & Frequency & $\begin{array}{l}\text { Valid } \\
\text { Pct. }\end{array}$ & $\begin{array}{l}\text { Wghtd } \\
\text { Valid Pct. }\end{array}$ & Missing & Frequency & $\begin{array}{l}\text { Valid } \\
\text { Pct. }\end{array}$ & $\begin{array}{c}\text { Wghtd } \\
\text { Valid Pct. }\end{array}$ \\
\hline Region & $0.0 \%$ & 2276 & & & $0.0 \%$ & 3171 & & \\
\hline San Francisco Bay Area & & 653 & $28.7 \%$ & $30.1 \%$ & & 1116 & $35.2 \%$ & $36.3 \%$ \\
\hline Central Valley & & 92 & $4.0 \%$ & $3.9 \%$ & & 190 & $6.0 \%$ & $6.7 \%$ \\
\hline Central Coast & & 106 & $4.7 \%$ & $3.7 \%$ & & 107 & $3.4 \%$ & $2.8 \%$ \\
\hline San Diego and Imperial & & 209 & $9.2 \%$ & $7.4 \%$ & & 342 & $10.8 \%$ & $8.9 \%$ \\
\hline Northern California & & 144 & $6.3 \%$ & $4.6 \%$ & & 174 & $5.5 \%$ & $3.9 \%$ \\
\hline South Coast & & 1072 & $47.1 \%$ & $50.2 \%$ & & 1242 & $39.2 \%$ & $41.5 \%$ \\
\hline Disadvantaged Community & $0.0 \%$ & 2276 & & & $0.0 \%$ & 3171 & & \\
\hline No & & 2085 & $91.6 \%$ & $91.3 \%$ & & 2942 & $92.8 \%$ & $92.2 \%$ \\
\hline Yes & & 191 & $8.4 \%$ & $8.7 \%$ & & 229 & $7.2 \%$ & $7.8 \%$ \\
\hline \multicolumn{9}{|l|}{ Motivational } \\
\hline $\begin{array}{l}\text { Importance of reducing } \\
\text { environmental impact }\end{array}$ & $0.9 \%$ & 2255 & & & $0.8 \%$ & 3147 & & \\
\hline Not at all important & & 64 & $2.8 \%$ & $2.8 \%$ & & 93 & $3.0 \%$ & $3.1 \%$ \\
\hline Slightly important & & 100 & $4.4 \%$ & $4.5 \%$ & & 149 & $4.7 \%$ & $4.8 \%$ \\
\hline Moderately important & & 349 & $15.5 \%$ & $15.5 \%$ & & 448 & $14.2 \%$ & $14.9 \%$ \\
\hline Very important & & 623 & $27.6 \%$ & $28.0 \%$ & & 757 & $24.1 \%$ & $24.6 \%$ \\
\hline Extremely important & & 1119 & $49.6 \%$ & $49.2 \%$ & & 1700 & $54.0 \%$ & $52.5 \%$ \\
\hline $\begin{array}{l}\text { Importance of increasing energy } \\
\text { independence }\end{array}$ & $1.3 \%$ & 2247 & & & $1.2 \%$ & 3133 & & \\
\hline Not at all important & & 116 & $5.2 \%$ & $5.3 \%$ & & 226 & $7.2 \%$ & $7.4 \%$ \\
\hline Slightly important & & 181 & $8.1 \%$ & $8.3 \%$ & & 293 & $9.4 \%$ & $9.6 \%$ \\
\hline Moderately important & & 531 & $23.6 \%$ & $23.5 \%$ & & 665 & $21.2 \%$ & $22.1 \%$ \\
\hline Very important & & 684 & $30.4 \%$ & $30.3 \%$ & & 879 & $28.1 \%$ & $27.8 \%$ \\
\hline Extremely important & & 735 & $32.7 \%$ & $32.6 \%$ & & 1070 & $34.2 \%$ & $33.0 \%$ \\
\hline $\begin{array}{l}\text { Importance of the convenience of } \\
\text { charging }\end{array}$ & $1.1 \%$ & 2250 & & & $1.3 \%$ & 3129 & & \\
\hline Not at all important & & 65 & $2.9 \%$ & $2.8 \%$ & & 91 & $2.9 \%$ & $2.9 \%$ \\
\hline Slightly important & & 211 & $9.4 \%$ & $9.2 \%$ & & 215 & $6.9 \%$ & $6.7 \%$ \\
\hline Moderately important & & 607 & $27.0 \%$ & $27.1 \%$ & & 788 & $25.2 \%$ & $24.9 \%$ \\
\hline Very important & & 796 & $35.4 \%$ & $35.0 \%$ & & 1173 & $37.5 \%$ & $37.7 \%$ \\
\hline Extremely important & & 571 & $25.4 \%$ & $26.0 \%$ & & 862 & $27.5 \%$ & $27.8 \%$ \\
\hline $\begin{array}{l}\text { Importance of access to the carpool } \\
\text { or HOV lane }\end{array}$ & $1.3 \%$ & 2247 & & & $0.9 \%$ & 3141 & & \\
\hline Not at all important & & 226 & $10.1 \%$ & $8.9 \%$ & & 443 & $14.1 \%$ & $13.5 \%$ \\
\hline Slightly important & & 288 & $12.8 \%$ & $11.9 \%$ & & 513 & $16.3 \%$ & $15.8 \%$ \\
\hline Moderately important & & 489 & $21.8 \%$ & $21.1 \%$ & & 690 & $22.0 \%$ & $21.5 \%$ \\
\hline Very important & & 433 & $19.3 \%$ & $20.1 \%$ & & 579 & $18.4 \%$ & $18.5 \%$ \\
\hline Extremely important & & 811 & $36.1 \%$ & $37.9 \%$ & & 916 & $29.2 \%$ & $30.7 \%$ \\
\hline
\end{tabular}


Table A1. Cont.

\begin{tabular}{|c|c|c|c|c|c|c|c|c|}
\hline & \multicolumn{4}{|c|}{ PHEV } & \multicolumn{4}{|c|}{ BEV } \\
\hline & Missing & Frequency & $\begin{array}{l}\text { Valid } \\
\text { Pct. }\end{array}$ & $\begin{array}{c}\text { Wghtd } \\
\text { Valid Pct. }\end{array}$ & Missing & Frequency & $\begin{array}{l}\text { Valid } \\
\text { Pct. }\end{array}$ & $\begin{array}{c}\text { Wghtd } \\
\text { Valid Pct. }\end{array}$ \\
\hline $\begin{array}{l}\text { Importance of saving money on } \\
\text { fuel }\end{array}$ & $1.5 \%$ & 2241 & & & $1.5 \%$ & 3125 & & \\
\hline Not at all important & & 25 & $1.1 \%$ & $1.1 \%$ & & 66 & $2.1 \%$ & $2.0 \%$ \\
\hline Slightly important & & 126 & $5.6 \%$ & $5.4 \%$ & & 269 & $8.6 \%$ & $8.1 \%$ \\
\hline Moderately important & & 406 & $18.1 \%$ & $17.7 \%$ & & 665 & $21.3 \%$ & $20.8 \%$ \\
\hline Very important & & 656 & $29.3 \%$ & $29.1 \%$ & & 953 & $30.5 \%$ & $30.4 \%$ \\
\hline Extremely important & & 1028 & $45.9 \%$ & $46.7 \%$ & & 1172 & $37.5 \%$ & $38.7 \%$ \\
\hline Importance of vehicle style & $1.3 \%$ & 2247 & & & $1.1 \%$ & 3137 & & \\
\hline Not at all important & & 40 & $1.8 \%$ & $1.6 \%$ & & 130 & $4.1 \%$ & $4.2 \%$ \\
\hline Slightly important & & 202 & $9.0 \%$ & $9.0 \%$ & & 361 & $11.5 \%$ & $11.3 \%$ \\
\hline Moderately important & & 516 & $23.0 \%$ & $22.2 \%$ & & 968 & $30.9 \%$ & $30.2 \%$ \\
\hline Very important & & 920 & $40.9 \%$ & $41.1 \%$ & & 1031 & $32.9 \%$ & $33.3 \%$ \\
\hline Extremely important & & 569 & $25.3 \%$ & $26.2 \%$ & & 647 & $20.6 \%$ & $21.1 \%$ \\
\hline Importance of vehicle performance & $1.5 \%$ & 2242 & & & $1.2 \%$ & 3132 & & \\
\hline Not at all important & & 47 & $2.1 \%$ & $2.1 \%$ & & 81 & $2.6 \%$ & $2.7 \%$ \\
\hline Slightly important & & 146 & $6.5 \%$ & $6.4 \%$ & & 232 & $7.4 \%$ & $7.6 \%$ \\
\hline Moderately important & & 554 & $24.7 \%$ & $24.7 \%$ & & 824 & $26.3 \%$ & $26.7 \%$ \\
\hline Very important & & 872 & $38.9 \%$ & $39.0 \%$ & & 1214 & $38.8 \%$ & $38.2 \%$ \\
\hline Reasons Pulled & $6.3 \%$ & 2132 & & & $6.4 \%$ & 2969 & & \\
\hline No reasons & & 606 & $28.4 \%$ & $29.7 \%$ & & 637 & $21.5 \%$ & $21.9 \%$ \\
\hline 1 reason & & 661 & $31.0 \%$ & $30.4 \%$ & & 949 & $32.0 \%$ & $32.0 \%$ \\
\hline 2 or more reasons & & 865 & $40.6 \%$ & $39.9 \%$ & & 1383 & $46.6 \%$ & $46.1 \%$ \\
\hline Reasons Pushed & $6.3 \%$ & 2132 & & & $6.4 \%$ & 2969 & & \\
\hline No reasons & & 410 & $19.2 \%$ & $18.0 \%$ & & 675 & $22.7 \%$ & $22.2 \%$ \\
\hline 1 reason & & 1140 & $53.5 \%$ & $54.0 \%$ & & 1601 & $53.9 \%$ & $54.0 \%$ \\
\hline 2 or more reasons & & 582 & $27.3 \%$ & $28.0 \%$ & & 693 & $23.3 \%$ & $23.8 \%$ \\
\hline \multicolumn{9}{|l|}{ Transactional } \\
\hline Time spent researching an EV & $0.0 \%$ & 2276 & & & $0.0 \%$ & 3171 & & \\
\hline $\begin{array}{l}\text { I did not spend any time } \\
\text { researching PEVs on the } \\
\text { internet }\end{array}$ & & 246 & $10.8 \%$ & $11.5 \%$ & & 385 & $12.1 \%$ & $13.6 \%$ \\
\hline Less than $4 \mathrm{~h}$ & & 470 & $20.7 \%$ & $21.2 \%$ & & 704 & $22.2 \%$ & $23.1 \%$ \\
\hline Between 4 to $12 \mathrm{~h}$ & & 881 & $38.7 \%$ & $38.3 \%$ & & 1044 & $32.9 \%$ & $32.5 \%$ \\
\hline More than $12 \mathrm{~h}$ & & 679 & $29.8 \%$ & $29.0 \%$ & & 1038 & $32.7 \%$ & $30.9 \%$ \\
\hline $\begin{array}{l}\text { Heard about CVRP from the } \\
\text { dealership }\end{array}$ & $0.0 \%$ & 2276 & & & $0.0 \%$ & 3171 & & \\
\hline No & & 1118 & $49.1 \%$ & $47.7 \%$ & & 1601 & $50.5 \%$ & $49.5 \%$ \\
\hline Yes & & 1158 & $50.9 \%$ & $52.3 \%$ & & 1570 & $49.5 \%$ & $50.5 \%$ \\
\hline Rebate Essential & $1.1 \%$ & 2251 & & & $0.6 \%$ & 3152 & & \\
\hline No & & 1171 & $52.0 \%$ & $51.8 \%$ & & 1133 & $35.9 \%$ & $33.8 \%$ \\
\hline Yes & & 1080 & $48.0 \%$ & $48.2 \%$ & & 2019 & $64.1 \%$ & $66.2 \%$ \\
\hline
\end{tabular}


Table A1. Cont.

\begin{tabular}{|c|c|c|c|c|c|c|c|c|}
\hline & \multicolumn{4}{|c|}{ PHEV } & \multicolumn{4}{|c|}{ BEV } \\
\hline & Missing & Frequency & $\begin{array}{c}\text { Valid } \\
\text { Pct. }\end{array}$ & $\begin{array}{c}\text { Wghtd } \\
\text { Valid Pct. }\end{array}$ & Missing & Frequency & $\begin{array}{c}\text { Valid } \\
\text { Pct. }\end{array}$ & $\begin{array}{c}\text { Wghtd } \\
\text { Valid Pct. }\end{array}$ \\
\hline Increased or standard rebate & $0.0 \%$ & 2276 & & & $0.0 \%$ & 3171 & & \\
\hline Standard Rebate & & 2051 & $90.1 \%$ & $89.9 \%$ & & 2872 & $90.6 \%$ & $89.9 \%$ \\
\hline Increased Rebate & & 225 & $9.9 \%$ & $10.1 \%$ & & 299 & $9.4 \%$ & $10.1 \%$ \\
\hline Purchase or Lease & $0.0 \%$ & 2276 & & & $0.0 \%$ & 3171 & & \\
\hline Lease & & 1110 & $48.8 \%$ & $58.5 \%$ & & 2203 & $69.5 \%$ & $76.3 \%$ \\
\hline Purchase & & 1166 & $51.2 \%$ & $41.5 \%$ & & 968 & $30.5 \%$ & $23.7 \%$ \\
\hline PHEV Make & $0.0 \%$ & 2276 & & & & & & \\
\hline Chevrolet & & 1035 & $45.5 \%$ & $47.9 \%$ & & & & \\
\hline Toyota & & 632 & $27.8 \%$ & $22.4 \%$ & & & & \\
\hline Other PHEV makes & & 609 & $26.8 \%$ & $29.7 \%$ & & & & \\
\hline BEV Makes & & & & & $0.0 \%$ & 3171 & & \\
\hline Chevrolet & & & & & & 678 & $21.4 \%$ & $15.2 \%$ \\
\hline Tesla & & & & & & 573 & $18.1 \%$ & $17.6 \%$ \\
\hline Other BEV makes & & & & & & 1920 & $60.5 \%$ & $67.2 \%$ \\
\hline
\end{tabular}

\section{References}

1. Tal, G.; Nicholas, M.A. Studying the PEV market in california: Comparing the PEV, PHEV and hybrid markets. In Proceedings of the 2013 World Electric Vehicle Symposium and Exhibition, EVS27, Barcelona, Spain, 17-20 November 2013; Institute of Electrical and Electronics Engineers Inc.: New York, NY, USA, 2013. [CrossRef]

2. Axsen, J.; Goldberg, S.; Bailey, J. How might potential future plug-in electric vehicle buyers differ from current "Pioneer" owners? Transp. Res. Part D Transp. Environ. 2016, 47, 357-370. [CrossRef]

3. Dua, R.; White, K.; Lindland, R. Understanding potential for battery electric vehicle adoption using large-scale consumer profile data. Energy Rep. 2019, 5, 515-524. [CrossRef]

4. Lee, J.H.; Hardman, S.J.; Tal, G. Who is buying electric vehicles in California? Characterising early adopter heterogeneity and forecasting market diffusion. Energy Res. Soc. Sci. 2019, 55, 218-226. [CrossRef]

5. Pallonetti, N.; Williams, B.D.H. Presentation: "What Vehicles Are Electric Vehicles Replacing and Why?". In Proceedings of the Behavior, Energy \& Climate Change Conference: Charging into the Future, Sacramento, CA, USA, 19 November 2019; BECC: Sacramento, CA, USA, 2019. Available online: https://becconference.org/wp-content/uploads/2019/11/agenda_presentations. pdf (accessed on 7 February 2020).

6. Williams, B.D.H.; Anderson, J.B.; Lastuka, A. Characterizing Plug-in Hybrid Electric Vehicle Consumers Who Found the U.S. Federal Tax Credit Extremely Important in Enabling Their Purchase. In Proceedings of the 33rd Electric Vehicle Symposium (EVS33); Electric Drive Transportation Association (EDTA), EVS33, Portland, OR, USA, 14-17 June 2020; Zenodo: Portland, OR, USA, 2020. [CrossRef]

7. Program Reports I Clean Vehicle Rebate Project. Available online: https:/ / cleanvehiclerebate.org/eng/program-reports (accessed on 8 March 2020).

8. Hardman, S.; Shiu, E.; Steinberger-Wilckens, R. Comparing high-end and low-end early adopters of battery electric vehicles. Transp. Res. Part A Policy Pract. 2016, 88, 40-57. [CrossRef]

9. Hardman, S.; Tal, G. Exploring the Decision to Adopt a High-End Battery Electric Vehicle: Role of Financial and Nonfinancial Motivations. Transp. Res. Rec. J. Transp. Res. Board 2016, 2572, 20-27. [CrossRef]

10. Langbroek, J.H.M.; Franklin, J.P.; Susilo, Y.O. The effect of policy incentives on electric vehicle adoption. Energy Policy 2016, 94, 94-103. [CrossRef]

11. Jabbari, P.; Chernicoff, W.; Mackenzie, D. Analysis of electric vehicle purchaser satisfaction and rejection reasons. Transp. Res. Rec. 2017, 2628, 110-119. [CrossRef]

12. Johnson, C.; Williams, B.D.; Hsu, C.; Anderson, J.B. Anderson, Summary Documentation of the Electric Vehicle Consumer Survey, 20132015 Edition I Clean Vehicle Rebate Project; Center for Sustainable Energy (CSE): San Diego, CA, USA, 2017; Available online: https: / / cleanvehiclerebate.org/eng/content/summary-documentation-electric-vehicle-consumer-survey-2013-2015-edition (accessed on 5 February 2020).

13. Axsen, J.; Cairns, J.; Dusyk, N.; Goldberg, S. What drives the Pioneers? Applying lifestyle theory to early electric vehicle buyers in Canada. Energy Res. Soc. Sci. 2018, 44, 17-30. [CrossRef] 
14. Westin, K.; Jansson, J.; Nordlund, A. The importance of socio-demographic characteristics, geographic setting, and attitudes for adoption of electric vehicles in Sweden. Travel Behav. Soc. 2018, 13, 118-127. [CrossRef]

15. Williams, B.D.; Orose, J.; Jones, M.; Anderson, J.B. Anderson, Summary of Disadvantaged Community Responses to the Electric Vehicle Consumer Survey, 2013-2015 Edition I Clean Vehicle Rebate Project; Center for Sustainable Energy (CSE): San Diego, CA, USA, 2018; Available online: https://cleanvehiclerebate.org/eng/content/summary-disadvantaged-community-responses-electric-vehicleconsumer-survey-2013--2015-edition (accessed on 1 July 2020).

16. Brownstone, D.; Bunch, D.S.; Train, K. Joint mixed logit models of stated and revealed preferences for alternative-fuel vehicles. Transp. Res. Part B Methodol. 2000, 34, 315-338. [CrossRef]

17. Wolinetz, M.; Axsen, J. How policy can build the plug-in electric vehicle market: Insights from the REspondent-based Preference And Constraints (REPAC) model. Technol. Forecast. Soc. Chang. 2017, 117, 238-250. [CrossRef]

18. Jia, W.; Chen, T.D. Are Individuals' stated preferences for electric vehicles (EVs) consistent with real-world EV ownership patterns? Transp. Res. Part D Transp. Environ. 2021, 93, 102728. [CrossRef]

19. de Rubens, G.Z. Who will buy electric vehicles after early adopters? Using machine learning to identify the electric vehicle mainstream market. Energy 2019, 172, 243-254. [CrossRef]

20. Kurani, K.S. State of the Plug-In Electric Vehicle Market: Report I; National Center for Sustainable Transportation: Davis, CA, USA, 2018; Available online: https:/ / escholarship.org/uc/item/4gn9x59z (accessed on 11 February 2021).

21. Kurani, K.S. State of the Plug-In Electric Vehicle Market: Report II; National Center for Sustainable Transportation (NCST): Davis, CA, USA, 2018; Available online: https:/ / escholarship.org/uc/item/8rp9h6fb (accessed on 16 February 2021).

22. Williams, B.D.; Johnson, C. Presentation: "Characterizing California Electric Vehicle Consumer Segments," in BECC Conference ACEEE, UC Berkeley CIEE, and SEEPAC, Baltimore. 2016. Available online: https://beccconference.org/presentations_2016/ (accessed on 1 July 2020).

23. Johnson, C.; Williams, B.D. Characterizing Plug-In Hybrid Electric Vehicle Consumers Most Influenced by California's Electric Vehicle Rebate. Transp. Res. Rec. 2017, 2628, 23-31. [CrossRef]

24. Williams, B.D.; Anderson, J.B. Strategically Targeting Plug-in Electric Vehicle Rebates and Outreach Using Characteristics of 'Rebate-Essential" Consumers in 2016-2017. In Proceedings of the 31st International Electric Vehicle Symposium; Society of Automotive Engineers of Japan, Inc.: Kobe, Japan, 2018; Available online: https:/ / energycenter.org/sites/default/files/docs/nav/resources / EVS31_TargetingRebateEssentialConsumers_revised.pdf (accessed on 25 February 2021).

25. Williams, B.D.H.; Anderson, J.B. Presentation: “Growing the Electric Vehicle Market: EV Adopters, 'Rebate Essentials,' and ‘EV Converts'". In Proceedings of the Roadmap 12 Conference, Portland, OR, USA, 19 June 2019; Forth: Portland, OR, USA, 2019. Available online: https: / / cleanvehiclerebate.org/eng/content/presentation-\%E2\%80\%9Cgrowing-electric-vehicle-market-evadopters-\%E2\%80\%98rebate-essentials\%E2\%80\%99-and-\%E2\%80\%98ev (accessed on 5 February 2020).

26. Williams, B.D.; Johnson, C. Poster: "Characterizing California Electric Vehicle Consumer Segments". In Proceedings of the TRB Annual Meeting; Transportation Research Board, National Research Council, National Academy of Sciences: Washington, DC, USA, 2017; Available online: https:/ / cleanvehiclerebate.org/eng/content/infographic-characterizing-california-electric-vehicleconsumer-segments-trb-poster (accessed on 5 February 2020).

27. CSE. AA Advanced Technology Vehicle Sales Dashboard I Auto Alliance. 2019. Available online: https://autoalliance.org/ energy-environment/advanced-technology-vehicle-sales-dashboard/ (accessed on 5 February 2020).

28. CVRP. EV Consumer Survey Dashboard I Clean Vehicle Rebate Project. 2019. Available online: https://cleanvehiclerebate.org/ eng/survey-dashboard/ev (accessed on 5 February 2020).

29. Anderson, J.B.; Williams, B.D.H.; Havel, K. Data: “California Clean Vehicle Rebate Project Application and Consumer Survey Data: Data used in a 2020 analysis of 'EV Converts'”. Mendeley Data 2021, V2. [CrossRef]

30. CVRP. Income Eligibility I Clean Vehicle Rebate Project. Available online: https://cleanvehiclerebate.org/eng/income-eligibility (accessed on 8 March 2020).

31. Solon, G.; Haider, S.J.; Wooldridge, J.M. What Are We Weighting For? J. Hum. Resour. 2015, 50, 301-316. [CrossRef]

32. Jin, L.; Searle, S.; Lutsey, N. Lutsey, Evaluation of State-Level U.S. Electric Vehicle Incentives; The International Council on Clean Transportation (ICCT): Washington DC, USA, 2014; Available online: https://theicct.org/sites/default/files/publications/ICCT_ state-EV-incentives_20141030.pdf (accessed on 9 March 2020).

33. Smart, J.G.; Salisbury, S.D. Plugged in: How Americans Charge Their Electric Vehicles; Office of Scientific and Technical Information (\{OSTI\}): Idaho Falls, ID, USA, 2015. [CrossRef]

34. Williams, B.D.; Anderson, J.B.; Santulli, C.; Arreola, G. Arreola, Clean Vehicle Rebate Project Participation Rates: The First Five Years; Clean Vehicle Rebate Project (CVRP): San Diego CA, USA, 2015; Available online: https:/ / cleanvehiclerebate.org/eng/content/ cvrp-participation-thru-2015-03 (accessed on 1 July 2020).

35. Santulli, C.; Williams, B.D. Presentation: "Implementation Status Update" | Clean Vehicle Rebate Project. In CVRP Long-Term Plan Work; California Air Resources Board (CARB): Sacramento, CA, USA, 2015; Available online: https: / cleanvehiclerebate.org/ eng/content/implementation-update-dec-2015 (accessed on 5 February 2020).

36. Kurani, K.S.; Caperello, N.; TyreeHageman, J. New Car Buyers' Valuation of Zero-Emission Vehicles: California; ITS-UCDavis: Davis, CA, USA, 2016; Available online: https: / its.ucdavis.edu/research/publications/?frame=https\%3A\%2F\%2Fitspubs.ucdavis edu\%2Findex.php\%2Fresearch\%2Fpublications\%2Fpublication-detail\%2F\%3Fpub_id\%3D2682 (accessed on 9 March 2020). 
37. Williams, B.D.; Johnson, C. Presentation: “EV Consumer Characteristics, Awareness, Information Channels \& Motivations". In Proceedings of the EV Roadmap 9 Conference, Portland, OR, USA, 20-21 June 2016; Available online: http:/ / roadmapforth.org/ program/index16.php (accessed on 1 July 2020).

38. CSE. Infographic: What Drives California's Plug-in Electric Vehicle Owners? I Clean Vehicle Rebate Project. 2016. Available online: https:/ / cleanvehiclerebate.org/eng/content/infographic-what-drives-california-plug-electric-vehicle-owners (accessed on 5 February 2020).

39. Hair, J.F.; Black, W.C.; Babin, B.J.; Anderson, R.E. Multivariate Data Analysis, 7th ed.; Prentice Hall: Upper Saddle River, NJ, USA, 2010.

40. Williams, R. Ordinal Independent Variables, University of Notre Dame, Notre Dame. 2019. Available online: https:/ /www3.nd edu/ \{\}rwilliam/stats3/OrdinalIndependent.pdf (accessed on 25 February 2021).

41. Yan, T.; Jans, M.; Curtin, R. Curtin, Changes in Nonresponse to Income Questions, AAPOR-ASA Section on Survey Research Methods. 2006, pp. 4270-4277. Available online: http://www.asasrms.org/Proceedings/y2006/Files/JSM2006-000317.pdf (accessed on 1 July 2020).

42. Stata. Stata Multiple-Imputation Reference Manual, Release 13, StataCorp LP. 2013. Available online: https:/ /www.stata.com/ manuals13/mi.pdf (accessed on 1 July 2020).

43. Williams, R. Understanding and interpreting generalized ordered logit models. J. Math. Sociol. 2016, 40, 7-20. [CrossRef]

44. Rubin, D.B. Multiple Imputation for Nonresponse in Surveys, Wiley-Interscience. 2004. Available online: https:/ /books.google. $\mathrm{com} /$ books?hl=en\&lr=\&id=bQBtw6rx_mUC\&oi=fnd\&pg=PR24\&dq=Rubin, +D.+B.+(2004).+Multiple+imputation + for + nonresponse+in+surveys.+Hoboken,+N.J:+Wiley-Interscience\&ots=8OvIdK60gQ\&sig=KYcQT7yT18W1H2uMQaOzrSQTj50 (accessed on 9 March 2020).

45. van Buuren, S.; Groothuis-Oudshoorn, K. mice: Multivariate imputation by chained equations in R. J. Stat. Softw. 2011, 45, 1-67. [CrossRef]

46. Kassambara, A. Logistic Regression Assumptions and Diagnostics in R. In Machine Learning Essentials: Practical Guide in R; STHDA, 2017; Available online: http:/ / www.sthda.com/english/articles/36-classification-methods-essentials/148-logisticregression-assumptions-and-diagnostics-in-r/\#logistic-regression-assumptions (accessed on 25 February 2021).

47. Azen, R.; Traxel, N. Using Dominance Analysis to Determine Predictor Importance in Logistic Regression. J. Educ. Behav. Stat. 2009, 34, 319-347. [CrossRef]

48. Soares, F.C. Exploring Predictors' Importance in Binomial Logistic Regressions. 2020. Available online: https:/ / cran.r-project. $\mathrm{org}$ /web/packages/dominanceanalysis/vignettes/da-logistic-regression.html (accessed on 9 March 2020).

49. NREL. 2017 National Household Travel Survey-California Add-On I Transportation Secure Data Center I NREL. 2019. Available online: https: / www.nrel.gov/transportation/secure-transportation-data/tsdc-nhts-california.html (accessed on 8 March 2020).

50. Beak, Y.; Kim, K.; Maeng, K.; Cho, Y. Is the environment-friendly factor attractive to customers when purchasing electric vehicles? Evidence from South Korea. Bus. Strateg. Environ. 2020, 29, 996-1006. [CrossRef]

51. Williams, B.D.H. Presentation: "Electric Vehicle Incentives and Policies". In National Governors Association Maryland Grid Modernization Retreat, November 2019; National Governors Association: Hanover, MD, USA, 2019; Available online: https: //www.nga.org/center/meetings/maryland-grid-modernization-retreat/ (accessed on 1 July 2020).

52. Williams, B.D.H. Presentation: “Transportation Electrification: Incentives”. In Proceedings of the REV2019 Conference, South Burlington, VT, USA, 10-11 October 2019; Available online: https:/ / energycenter.org/sites/default/files/docs/nav/resources / Evaluating_and_Maximizing_Electric_Vehicle_Incentive_Impacts_and_Accelerating_Net_Zero_Transportation.pdf (accessed on 1 July 2020).

53. Slowik, P. Expanding Zero-Emission Mobility Equity and Access Workshop Report. 2019. Available online: http://www. zevalliance.org/expanding-zev-access / (accessed on 6 February 2020). 